\title{
Utilization of a Novel Low-Cost Gibto (Lupinus Albus) Seed Peel Waste for the Removal of Malachite Green Dye: Equilibrium, Kinetic, and Thermodynamic Studies
}

\author{
Adugna Nigatu Alene $\mathbb{D}^{1},{ }^{1}$ Gietu Yirga Abate $\mathbb{D}^{\mathbb{D}},{ }^{2}$ Adere Tarekegne Habte $\mathbb{D}^{\mathrm{D}},{ }^{2}$ \\ and Desiew Mekuanint Getahun ${ }^{2}{ }^{2}$ \\ ${ }^{1}$ Faculty of Chemical and Food Engineering, Bahir Dar Institute of Technology, Bahir Dar University, Bahir Dar, Ethiopia \\ ${ }^{2}$ Department of Chemistry, Woldia University, Woldia, Ethiopia \\ Correspondence should be addressed to Adugna Nigatu Alene; adugnanigatu123@gmail.com
}

Received 30 November 2020; Revised 6 February 2021; Accepted 15 March 2021; Published 24 March 2021

Academic Editor: Ester Chiessi

Copyright (C) 2021 Adugna Nigatu Alene et al. This is an open access article distributed under the Creative Commons Attribution License, which permits unrestricted use, distribution, and reproduction in any medium, provided the original work is properly cited.

\begin{abstract}
The aim of this study was to investigate the adsorption characteristics of malachite green (MG) dye onto the raw (RLAPW) and activated (ALAPW) surface of Lupinus albus seed peel waste prepared via physicochemical activation under alkaline condition as a dye adsorbent. Proximate analysis, surface area (Sears' method), point of zero charge (pHzpc), and FTIR analysis were used to characterize the adsorbents. The effects of operational parameters such as pH (4) for ALAPW and pH (6) for RLAPW, adsorbent dose $(0.2 \mathrm{~g})$, initial dye concentration $(30 \mathrm{mg} / \mathrm{L})$, contact time $(60 \mathrm{~min})$, and temperature $(298 \mathrm{~K})$ were optimized. The experimental data well fitted with the Freundlich adsorption isotherm with the adsorption capacity of $7.3 \mathrm{mg} / \mathrm{g}$ for activated Lupinus albus seed peel waste (ALAPW) and Sips isotherm for raw Lupinus albus seed peel waste (RLAPW) with the adsorption capacity of $6.6 \mathrm{mg} / \mathrm{g}$. The kinetics data well fitted to pseudo-second-order kinetic model for both adsorbents. Thermodynamic study revealed that the bioadsorption process using bioadsorbents was spontaneous and exothermic in nature. Desorption experiment was conducted and showed desorption efficiency at an acidic $\mathrm{pH}$ of 2 . The results showed that the prepared adsorbents exhibited good adsorption capacity and can be used as an alternative adsorbent for the adsorptive removal of malachite green dyes.
\end{abstract}

\section{Background}

The aquatic environment is significantly affected by the presence of various toxic chemicals such as dyes and pigments, metals, organics, and pharmaceuticals and is a major environmental concern due to industrialization and urbanization [1]. Colored effluents (mainly synthetic dyes) discharged from textiles, cosmetics, leather, pulp mills, printing, dye synthesis, food processing, hair dying, mineral processing, and plastic industries have become a major global problem [2,3]. Dyes are classified as cationic (basic dyes), anionic (acid, direct and reactive dyes), and nonionic (disperse dyes) dyes on the basis of their dissociation in an aqueous solution [1]. Most of these synthetic dyes are toxic/hazardous and have genotoxic, mutagenic, and carcinogenic effects on the aquatic life and human health $[4,5]$. Malachite green (MG) is a basic (cationic) dye containing triphenyl methane water soluble group, widely used for the dyeing of wool and silk, leather, paper, acrylic industries, and distilleries [6]. Malachite green (MG) is also used as an antimicrobial, antifungal, antiprotozoal, antiparasitic, and antiseptic agents in the aquacultural areas [7-9]. However, MG dye is environmentally persistent and highly toxic to aquatic and mammalian cells and also acts as carcinogenic, mutagenic, a liver tumor enhancing agent, and teratogenic effects on human health and biota [9-11]. Therefore, the removal of such synthetic dyes from effluents discharged from various industries is a great concern for the environmental viewpoint [12]. 
Appropriate methods of dye removal from various effluents such as physical (precipitation, membrane filtration, electrochemical destruction, ion exchange, irradiation, ozonation, and adsorption), chemical (coagulation and flocculation), and biological (decolourisation-fermentation) effluents are used in the removal of colored effluents (dyes) from waste water [13]. Amongst those possible methods, adsorption has been superior to others in terms of economic feasibility, simplicity of design, ease of operation, high efficiency, and insensitivity to toxic pollutants $[14,15]$.

According to different scholar findings, waste peels from agricultural areas are potential bioadsorbents for the removal of dyes due to their availability in nature, renewability, nontoxicity, easy conversion, and preparation with simple methods [16]. Some of the bioadsorbents, such as citrus limetta peel waste [17], yellow passion fruit peel [18], pomelo peel [19], garlic peel [15], lime peel [20], citrus peel [21], orange peel [22], banana peel [2], jackfruit peel [23], pomegranate peel [12], potato peel [23], rambutan peel [13], water chest nut peel [24], and green pea peel [25], are waste peels used to treat toxic pollutants. Agricultural wastes (adsorbents) aided the uptake of colored effluents (dyes) via various binding mechanisms (hydrogen bonding, electrostatic attraction, and $\pi-\pi$ interaction) due to the presence of various surface functional groups such as hydroxyl, carboxyl, carbonyl, amine, amide, alcohol, and phenol [16].

Gibto (Amharic name), Lupinus albus plant, is a member of the genus Lupinus in the family of Fabaceae mostly grown in northern Europe, Russia, Mediterranean countries, North America, Australia, and Africa (Kenya, South Africa, Tanzania, Zimbabwe, Mauritius, and Ethiopia) [26]. In Ethiopia, Gibto is a traditional crop mostly produced and consumed by small holder/scale farmers and mainly used for soil fertility maintenance values (green manure), food source, making local alcoholic drink "katikala" or "Gibto areke," and pharmaceutical issues. Before consumption, the Lupinus albus seeds are first roasted and soaked with running water for 3-5 days until the bitter taste (alkaloid part) is removed to make edible seeds. The edible seeds were consumed by mostly low-income classes, users of local alcoholic drinks, and as a traditional medicine by removing skin/peel part of the seed. The peels are directly disposed as a waste, and it is absolutely noneconomical. To our knowledge, there is no study that deals with waste peels of Lupinus albus being used for adsorbents for the removal of malachite green dye (cationic dye).

In this study, Gibto (Lupinus albus) seed peel waste (LAPW) was prepared by physicochemical activation and evaluated as a novel bioadsorbent for the removal of malachite green (MG) dye from aqueous solution. The adsorbents were characterized by proximate analysis, surface area (Sears' method), point of zero charge (pHzpc), and FTIR studies. The influence of experimental parameters such as $\mathrm{pH}$, adsorbent dose, contact time, temperature, and initial dye concentration was evaluated. The adsorption process (thermodynamics, kinetics, and isotherm models) and desorption study were performed.

\section{Materials and Methods}

2.1. Collection and Preparation of Materials. All the chemicals, malachite green dye (99\%, Sigma Aldrich), $\mathrm{NaCl}$ (99.9\%, SD Fine Chemicals Ltd., India), $\mathrm{HCl} \mathrm{(36-38 \% ,}$ Ranchem Industry and Trading, India), and $\mathrm{NaOH}$ (99.8\%, Alpha Chemicals, India) are analytical grade and used without further purification. Distilled water was used for the entire experimental procedures.

Lupinus albus seed peel waste adsorbents were prepared via physicochemical activation process (ALAPW) and without any activation (RLAPW) using the method reported in [26-30] with some modifications, and its process is presented in Figure 1. Gibto (Lupinus albus) seed peel wastes were collected in "Mesheta Bet" from Debre Markos town, Amhara regional state, Ethiopia, and washed with distilled water till the dirt species and soluble impurities were completely removed. The cleaned sample was allowed to dry at room temperature and oven-dried at $378 \mathrm{~K}$ until constant weight reached. The dried sample was crushed into small pieces, powdered, and sieved to $\leq 1 \mathrm{~mm}$ mesh size. The powder was physically activated in an oven at $573 \mathrm{~K}$ for 4 hours to develop porosity and enhance adsorption efficiency. Thereafter, the carbonized (physically activated) sample was soaked with $1 \mathrm{~N} \mathrm{NaOH}$ with an impregnated ratio of $1: 5 \mathrm{w} / \mathrm{v}$ for 24 hours for chemical activation. The activated sample was filtered, washed with distilled water repeatedly until the $\mathrm{pH}$ of the solution reached to neutral, dried at $378 \mathrm{~K}$ for 24 hours, and kept in a desiccator for further analysis.

\subsection{Description and Preparation of Malachite Green (MG)} Dye. Analytical grade malachite green (MG) dye (Scheme 1) was obtained from the chemistry laboratory, Woldia University, Ethiopia. Stock solution of the MG dye $(500 \mathrm{mg} / \mathrm{L})$ was prepared and further diluted to the experimental solutions of different concentrations ranging from $10-50 \mathrm{mg} /$ L. The maximum wavelength $(618 \mathrm{~nm})$ was obtained after scanning of the dye using UV/VIS spectrometer (Lamda 35 Perkin Elmer), and a standard curve was developed through the measurement of the MG dye solution absorbance and the maximum wavelength $(618 \mathrm{~nm})$.

2.3. Characterization of Adsorbents. The proximate analysis (moisture content (MC), ash content (AC), volatile matter (VM), and fixed carbon (FC)) that determines the characteristics of Lupinus albus seed peel waste adsorbents (RLAPW and ALAPW) was performed according to [27, 31-34]. Specific surface area (SA) of the adsorbents was analyzed by Sears' method [35]. In brief, $1.5 \mathrm{~g}$ of adsorbents and $30 \mathrm{~g} \mathrm{NaCl}$ were added in a $250 \mathrm{ml}$ conical flask and dissolved by $100 \mathrm{ml}$ of distilled water. Then, the $\mathrm{pH}$ of solutions was adjusted to 4 using $0.1 \mathrm{M} \mathrm{HCl}$, and the solutions were titrated by $0.1 \mathrm{M} \mathrm{NaOH}$ until $\mathrm{pH}$ of the solution reaches to 9. The volume of $\mathrm{NaOH}$ required to change $\mathrm{pH}$ value from 4 to 9 was recorded. The specific surface area of the adsorbents (RLAPW and ALAPW) was examined using the following formula: 


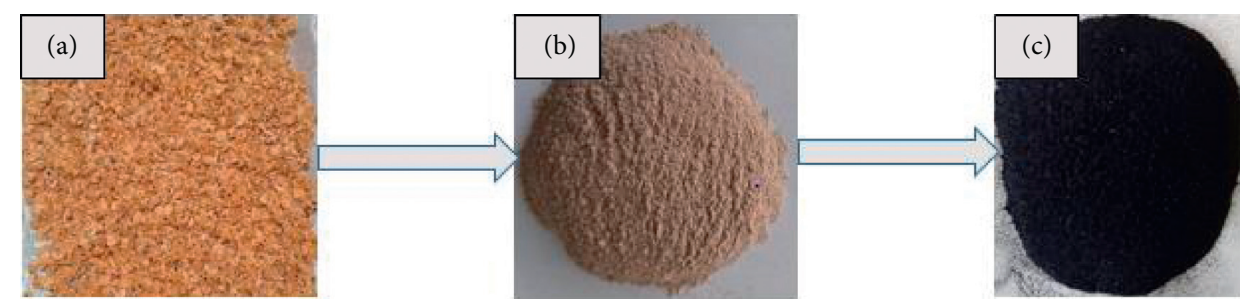

Figure 1: Lupinus albus seed peel waste (a), powdered Lupinus albus seed peel waste, RLAPW (b), and physicochemically activated Lupinus albus seed peel waste, ALAPW (c).

Properties

Molecular formula: $\mathrm{C}_{52} \mathrm{H}_{54} \mathrm{~N}_{4} \mathrm{O}_{12}$

Maximum wavelength: $618 \mathrm{~nm}$

Molecular weight: $927 \mathrm{~g} / \mathrm{mol}$

Type: basic dye

Common name: malachite green oxalate
Structure

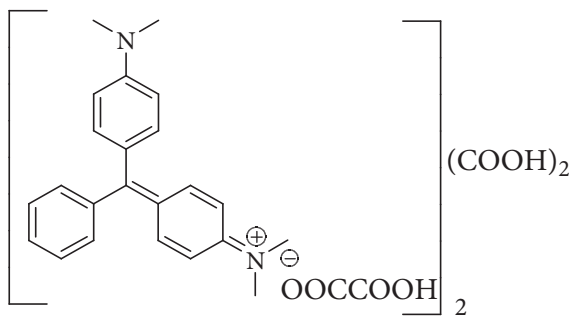

Scheme 1: Overview of malachite green (MG) dye.

$$
\text { specific surface area }\left(\frac{m^{2}}{g}\right)=32 \cdot V-25,
$$

where $V=$ volume of $\mathrm{NaOH}(0.1 \mathrm{M})$ required to raise the $\mathrm{pH}$ from 4-9.

The surface charge analysis (point of zero charge (pHzpc)) was evaluated according to [24, 36, 37]. In brief, $0.2 \mathrm{~g}$ of adsorbents and $50 \mathrm{~mL}$ of $0.1 \mathrm{M} \mathrm{NaCl}$ solution were placed into different $250 \mathrm{~mL}$ Erlenmeyer flasks. The initial $\mathrm{pH}$ of the mixtures were adjusted between 2 and 12 by the addition of $1 \mathrm{M} \mathrm{HCl}$ or $1 \mathrm{M} \mathrm{NaOH}$ solution and then left to equilibrate for $24 \mathrm{~h}$. The final $\mathrm{pH}$ of the solutions was measured and plotted the graph as $\mathrm{pH}$ final versus $\mathrm{pH}$ initial gave the pHzpc of the adsorbents. The surface functional groups of the adsorbents before and after adsorption were interpreted by Fourier transform infrared (FTIR) spectroscopy (Jasco-FT/IR-6600A), and the spectra in terms of percent transmittance were recorded in the range of $4000-400 \mathrm{~cm}^{-1}$.

2.4. Batch Adsorption Experiments. All adsorption experiments were carried out in batch mode by optimizing different variable parameters: $\mathrm{pH}(2-12)$, adsorbent dosage (0.0-0.4 g), initial dye concentration $(10-50 \mathrm{mg} / \mathrm{L})$, contact time $(10-70 \mathrm{~min})$, and temperature $(298 \mathrm{~K}-323 \mathrm{~K})$. The initial $\mathrm{pH}$ of all the solutions was adjusted with $1 \mathrm{M} \mathrm{NaOH}$ or $1 \mathrm{M} \mathrm{HCl}$. The solid-liquid separation was performed by centrifugation ( $4000 \mathrm{rpm}$ for $10 \mathrm{~min}$ ) followed by filtration. At the end of each experiment, a small amount of the solutions (supernatants) was withdrawn at predetermined time, and the absorbance was determined by using UV-vis spectrophotometer at a maximum wavelength of $618 \mathrm{~nm}$. The malachite green (MG) dye removal by the adsorbents
(\%) and the adsorption capacity at equilibrium, $q_{e}(\mathrm{mg} / \mathrm{g})$, are shown in equations (2) and (3), respectively [38-40].

$$
\begin{aligned}
\text { removal efficiency }(\%) & =\frac{C_{O}-C_{e}}{C_{O}} \times 100, \\
q_{e}\left(\frac{m g}{g}\right) & =\frac{\left(C_{O}-C_{e}\right) V}{m},
\end{aligned}
$$

where $C_{o}=$ initial concentration of $\mathrm{MG}$ dye $(\mathrm{mg} / \mathrm{L})$; $C_{e}=$ liquid-phase concentrations of the $\mathrm{MG}$ dye $(\mathrm{mg} / \mathrm{L})$ at equilibrium; $V=$ volume of the $\mathrm{MG}$ dye (L); and $m=$ adsorbent mass $(\mathrm{g})$.

2.5. Desorption Experiments. Desorption experiments are applicable to elucidate the nature of adsorption process and examine the possibility to recover adsorbate and to regenerate/recycle the adsorbent [41]. Desorption of MG dye was investigated on the adsorbents with preadsorbed dye at optimum conditions ( $\mathrm{pH} 4$ (ALAPW) and $\mathrm{pH} 6$ (RLAPW), adsorbent dose $0.2 \mathrm{~g}$, MG dye concentration $30 \mathrm{mgL}^{-1} / 50 \mathrm{~mL}$, contact time $60 \mathrm{~min}$, and temperature $298 \mathrm{~K}$ ), and the mixture was shaken with a magnetic stirrer on digital hot plate at $200 \mathrm{rpm}$. The preadsorbed MG dye and adsorbent was isolated from the mixture by centrifugation at $4000 \mathrm{rpm}$ for $5 \mathrm{~min}$ and then placed into $25 \mathrm{~mL}$ $\mathrm{Me}-\mathrm{OH}$ (99\%), $\mathrm{NaOH}(0.1 \mathrm{M})$, and $\mathrm{HCl}(0.1 \mathrm{M})$, at $\mathrm{pH} 2$. The suspensions were shaken on a rotary shaker at $150 \mathrm{rpm}$ for $24 \mathrm{hrs}$, and the supernatant solutions were analyzed using the UV-vis spectrophotometer. The amount of desorbed dye can be calculated by

$$
\text { desorption }(\%)=\frac{C * V}{q m} * 100 \text {, }
$$


where $C$ is MG dye concentration in the desorption solution $(\mathrm{mg} / \mathrm{L}), V$ is the volume of the desorption solution $(\mathrm{L}), q$ is the amount of MG dye adsorbed on the adsorbents before desorption experiment $(\mathrm{mg} / \mathrm{g})$, and $m$ is the amount of the adsorbent used in the desorption experiment $(\mathrm{g})$.

\section{Result and Discussion}

3.1. Characterization of Lupinus albus Seed Peel Waste Adsorbents (RLAPW and ALAPW). Physicochemical characteristics of the adsorbents such as proximate analysis, point of zero charge, and specific surface area are presented in Table 1. The moisture content (MC), ash content (AC), and volatile matter (VM) of ALAPW were found to be lower than RLAPW, whereas the fixed carbon (FC) content is higher than the RLAPW. This indicates that most of the moistures and heat-sensitive molecules present in the sample were removed up on physiochemical activation. The volatile matter of ALAPW was found to be low due to the organic components present in adsorbents which become less stable and the release of volatile matter as gas and liquid products which evaporates off leaving the material during the physicochemical activation process [27]. The ash content of ALAPW was also low, due to the removal of significant amount of mineral components, certain oxides, carbonates, and sulfides in the adsorbent during the physicochemical activation process [31]. The fixed carbon content of the ALAPW was high, which indicates the adsorbent material has good quality which enhances the surface area as well as the adsorption performance [33]. The specific surface area of the prepared adsorbent was $1703 \pm 0.56 \mathrm{~m}^{2} / \mathrm{g}$ and $1170 \pm 0.40 \mathrm{~m}^{2} / \mathrm{g}$ for ALAPW and RLAPW, respectively. The specific surface area of ALAPW was so high, indicating the adsorbent has good efficiency to adsorb a dye. Similar result was observed for methylene blue dye removal using activated carbon [42].

Point of zero charge (pHzpc) is explained as the situation in which the density of electric charge on the surface of the adsorbent becomes zero. The graph of $\mathrm{pHzpc}$ was plotted as "pH final versus $\mathrm{pH}$ initial," and the $\mathrm{pHzpc}$ values of the adsorbents was obtained at the intersection point of the curves of "pH final versus $\mathrm{pH}$ initial." The $\mathrm{pHzpc}$ plot of the adsorbents (ALAPW and RLAPW) is presented in Figure 2. The pHzpc was found to be 3.2 and 4.3 for ALAPW and RLAPW biosorbents, respectively. The low pHzpc for ALAPW may be due to the effects of physiochemical activation process. When $\mathrm{pH}<\mathrm{pHzpc}$, the adsorbents surface will become positively charged, and when the solution $\mathrm{pH}>\mathrm{pHzpc}$, the adsorbents surface will become negatively charged [43]. Below pHzpc, the surface of the adsorbents (ALAPW and RLAPW) becomes positively charged, and they compete with a cationic MG dye for vacant adsorption sites causing a decrease in dye uptake due to electrostatic repulsion. Above $\mathrm{pHzpc}$, the adsorbent surface is negatively charged and favors uptake of cationic MG dye due to increased electrostatic force of attraction [44].

3.2. FTIR Analysis. Fourier transform infrared (FT-IR) spectral analysis was conducted to determine the functional groups that exist on the surface of the materials. The FTIR spectra of RLAPW, ALAPW, RLAPW-loaded MG, and ALAPW loaded MG dye were recorded in the range of $4000-400 \mathrm{~cm}^{-1}$ and shown in Figure 3. In both spectra (before and after adsorption), the broad and intense adsorption peaks in the range of $3450-3350 \mathrm{~cm}^{-1}$ were obtained due to the hydroxyl $(-\mathrm{O}-\mathrm{H})$ or amine $(-\mathrm{N}-\mathrm{H})$ functional groups [2, 3, 45], the absorption peaks at $2950-2850 \mathrm{~cm}^{-1}$ can be reflected to the $-\mathrm{C}-\mathrm{H}$ group of alkane, stretching vibrations at $2400-2050 \mathrm{~cm}^{-1}$ assigned to $\mathrm{C} \equiv \mathrm{C}$ and $\mathrm{C} \equiv \mathrm{N}-\mathrm{H}$ bonds [20], the peaks at $1620-1610 \mathrm{~cm}^{-1}$ were attributed to stretching vibrations of carbonyl/carboxyl $(\mathrm{C}=\mathrm{O})$ groups [1], and intense peaks at $1460-1440 \mathrm{~cm}^{-1}$ are supposed to the presence of $(\mathrm{C}-\mathrm{H})$ vibration of aliphatic and aromatic groups and absorption bands in the range $1420-1000 \mathrm{~cm}^{-1}$ can be assigned to the $\mathrm{C}-\mathrm{O}$ and $\mathrm{C}-\mathrm{N}$ stretching vibration of carboxylic acids $(-\mathrm{COOH})$ and/or alcohols and amine groups [1-3].

The surface/characteristic peaks of RLAPW and ALAPW were found to be different (Figure 3 ) as some of the functional groups disappeared and the intensity of the peaks altered due to the physicochemical activation process, which shows that these functional groups were chemically protonated/deprotonated and thermally unstable [20]. The spectra of the RLAPW, ALAPW, RLAPW-loaded MG, and ALAPW-loaded MG dye showed similar characteristics of adsorption regions except for slight differences/changes. The FTIR spectra before and after adsorption indicate that the peaks are slightly shifted from their positions and the intensity gets changed. These results indicated the binding of some functional groups (hydroxyl, carbonyl, amine, and carboxyl) in the adsorption of malachite green (MG) dye on the adsorbents surface through weak electrostatic interaction or Van der Waals forces $[1,45]$. The FTIR spectral analysis revealed that both of the adsorbents (RLAPW and ALAPW) contain several functional groups such as hydroxyl, carbonyl, carboxyl, and amine groups, and these groups act as potential active sites for interaction with the malachite green (MG) dye. Those functional groups (potential active sites) were found in the adsorbents having high affinity towards pollutants (organic and inorganic), and the MG dye removal was carried via hydrogen bonding, electrostatic, and $\pi-\pi$ interactions [46].

\subsection{Batch Adsorption Study}

3.3.1. Effect of Solution $p H$. The effect of solution $\mathrm{pH}$ plays an important controlling parameter in the adsorption processes $[1,47]$. The effect of $\mathrm{pH}$ on the adsorption of $\mathrm{MG}$ dye by the ALAPW and RLAPW at pH between 2 and 12 is shown in Figure 4. The MG dye removal efficiency (Figure 4) was increased at the $\mathrm{pH}$ range of 2-4 for ALAPW and 2-6 for RLAPW at a given concentration. The adsorbent surface was positively charged at $\mathrm{pH}$ under 3.2 (ALAPW) and 4.3 (RLAPW) and showed negative charge over the pHzpc. The MG is a positively charged (cationic) dye and provides positive ions in the solutions. Thus, below pHzpc, the amounts of adsorption were lesser owing to electrostatic 
TABle 1: Proximate analyses of the adsorbents.

\begin{tabular}{|c|c|c|c|c|c|c|}
\hline \multirow{2}{*}{ Sample } & \multicolumn{6}{|c|}{ Characteristics } \\
\hline & Moisture content (\%) & Ash content (\%) & Volatile matter (\%) & Fixed carbon (\%) & Surface area $\left(\mathrm{m}^{2} / \mathrm{g}\right)$ & pHzpc \\
\hline RLAPW & $5.24 \pm 0.11$ & $8.23 \pm 0.05$ & $12.12 \pm 0.27$ & $74.41 \pm 0.13$ & $1170 \pm 0.40$ & $4.3 \pm 0.04$ \\
\hline ALAPW & $0.22 \pm 0.02$ & $3.25 \pm 0.01$ & $1.16 \pm 0.00$ & $95.4 \pm 0.28$ & $1703 \pm 0.56$ & $3.2 \pm 0.02$ \\
\hline
\end{tabular}

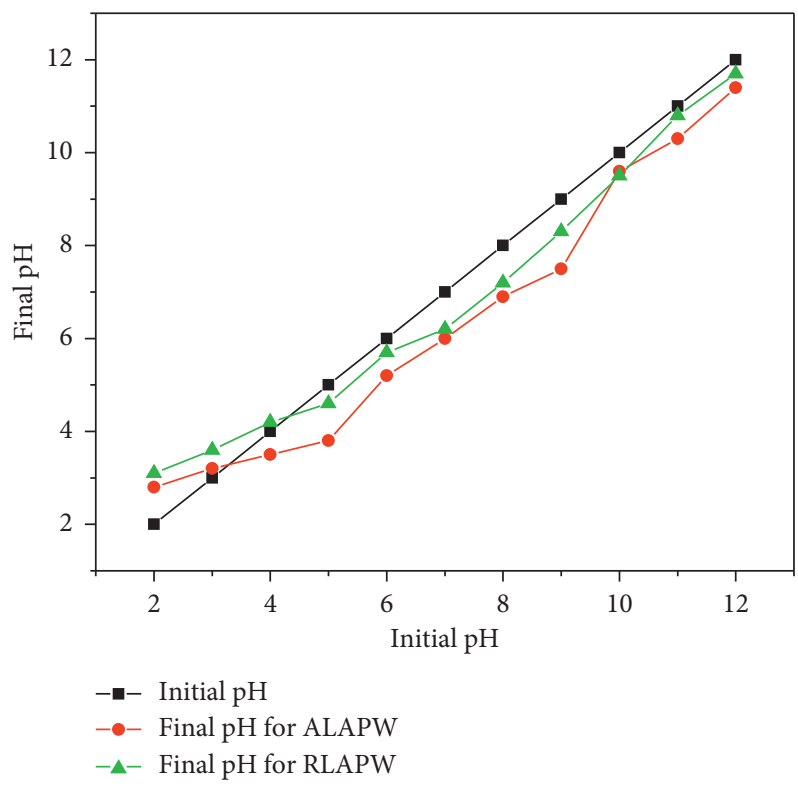

FIgURE 2: The pHzpc plot of the adsorbents (ALAPW and RLAPW).

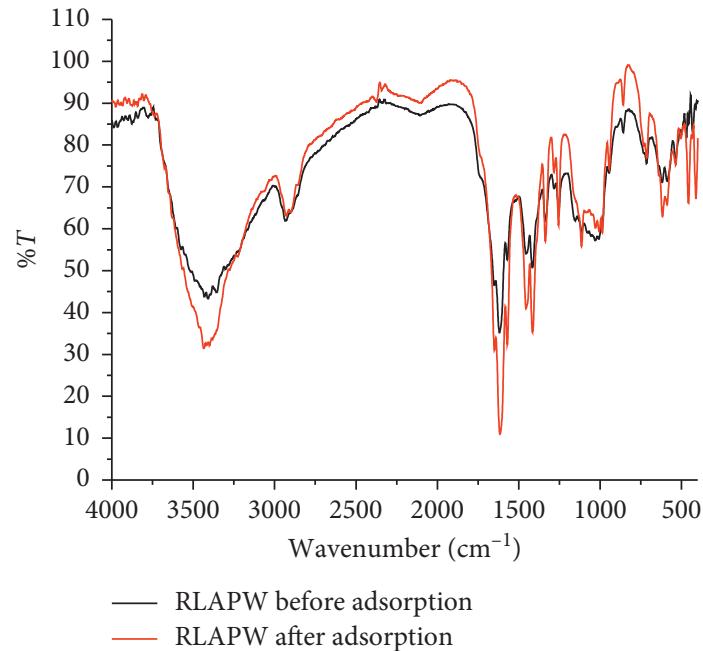

(a)

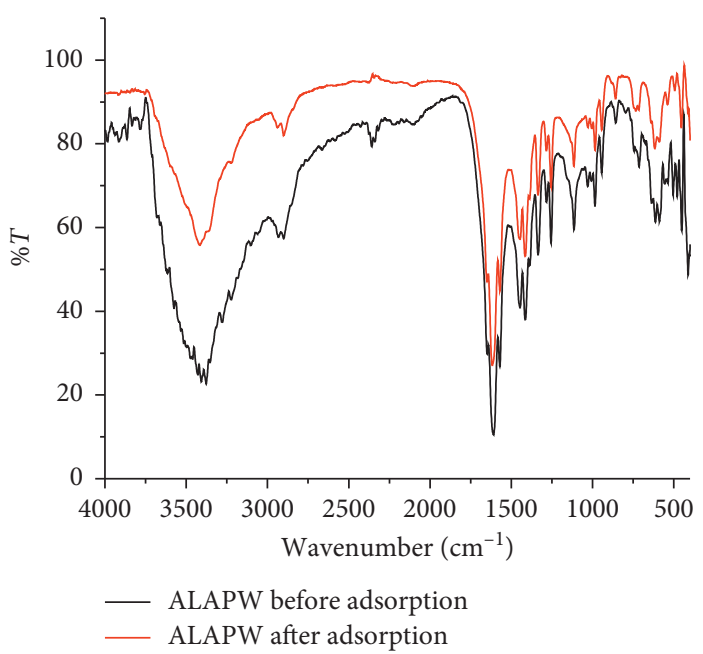

(b)

FIGURE 3: FT-IR spectra of LAPW adsorbents before and after adsorption of MG dye.

repulsion between the MG dye ions and the positively charged surface of the adsorbents.

The FT-IR analysis (Figure 3) showed that the ALAPW surface contained excess acidic functional groups due to physicochemical activation [30]. The FT-IR analysis also showed that the RLAPW surface contained acidic functional groups $\left(\mathrm{C}=\mathrm{O}\right.$ at $1617 \mathrm{~cm}^{-1}, \mathrm{O}-\mathrm{H}$ at $3407 \mathrm{~cm}^{-1}$, and $\mathrm{C}-\mathrm{O}$ at $\left.1028 \mathrm{~cm}^{-1}\right)$. The results revealed that the adsorption process 


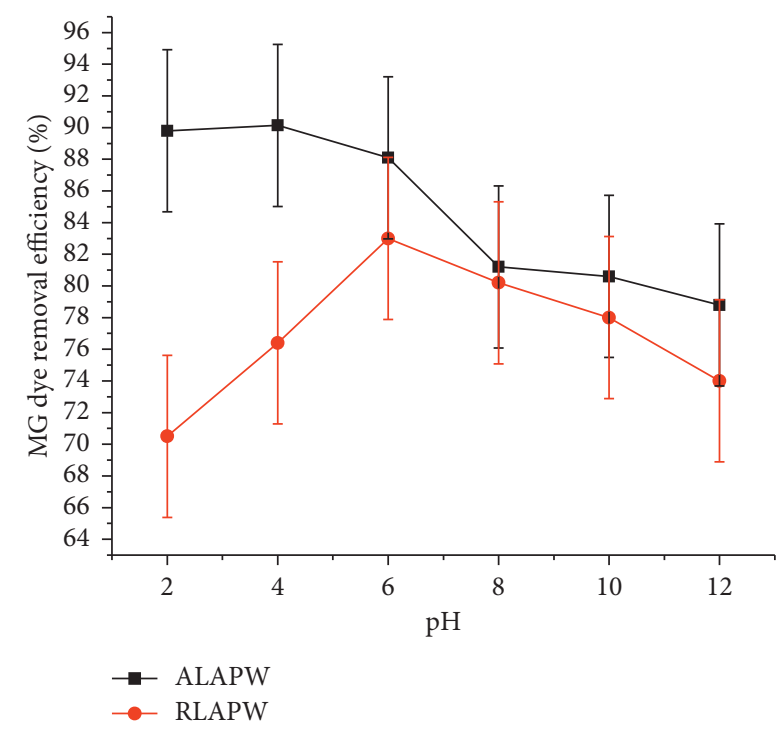

FIGURE 4: $\mathrm{pH}$ effect on the adsorption of MG dye by ALAPW and RLAPW at adsorbent dose $0.2 \mathrm{~g}$. MG dye concentration $10 \mathrm{mg} / \mathrm{L}$, contact time $60 \mathrm{~min}$, agitation speed $200 \mathrm{rpm}$, and room temperature $(298 \mathrm{~K})$.

may be carried out via a dominant acidic active surface of the adsorbents and the cationic MG dye. The high removal efficiency at lower $\mathrm{pH}$ (4) for ALAPW and $\mathrm{pH}$ (6) for RLAPW is probably due to electrostatic attraction, hydrogen bonding, or $\pi-\pi$ interaction between adsorbent and adsorbate (dye) [2]. In addition, the mechanism also responsible for the adsorption of MG may be more related to textural properties due to the presence of high surface area [14]. As a result, maximum MG dye removal efficiency was carried at acidic regions $(\mathrm{pH}<7)$. Similar behaviors were observed for malachite green dye adsorption on activated sintering process red mud $[10,48]$ and methylene blue cationic dye on jackfruit peel [49].

3.3.2. Effect of Adsorbent Dose. In the adsorption process, adsorbent dose is a very important parameter due to the dosage effect on the adsorbent and adsorbate [25]. The effect of adsorbent dose on the removal of MG dye by ALAPW and RLAPW is presented in Figure 5. When the adsorbents dose increased from 0.05 to $0.2 \mathrm{~g}$, an increase in the MG dye removal from 76.3 to $90.14 \%$ for ALAPW and 55.63 to $78.7 \%$ for RLAPW was observed. Such increase of MG dye removal with adsorbent dose is due to the presence of high surface area and availability of several adsorption sites in the adsorbents [16]. Beyond the optimum adsorbent dose (0.2 g), the MG dye removal was not significantly changed or affected due to conglomeration/aggregation of adsorbent particles which limits the active surfaces for adsorption [50].

3.3.3. Effect of Initial Dye Concentration. The effect of initial MG dye concentration on the adsorption of MG onto ALAPW and RLAPW was carried out in the concentration range of $10-50 \mathrm{mg} / \mathrm{L}$ as shown in Figure 6. Percent removal efficiency increased with an increase in MG dye

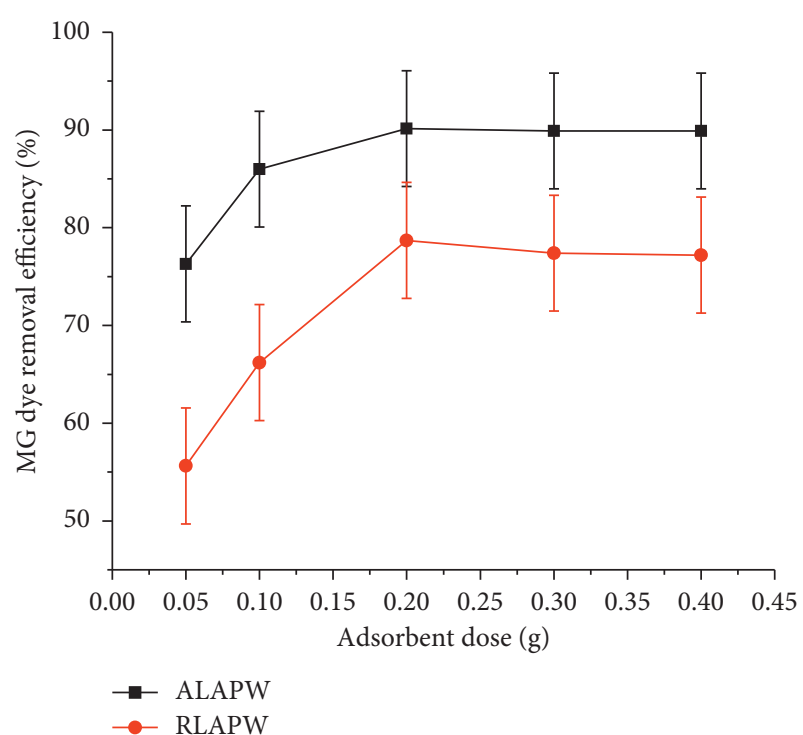

FIGURE 5: Effect of adsorbent dose on MG dye removal by ALAPW and RLAPW at pH 4 (ALAPW) and pH 6 (RLAPW), initial MG dye concentration $10 \mathrm{mg} / \mathrm{L}$, contact time $60 \mathrm{~min}$, and temperature $(298 \mathrm{~K})$ with agitation speed $200 \mathrm{rpm}$.

concentration from 10 to $30 \mathrm{mg} / \mathrm{L}$ for both adsorbents. The percent removal of MG dye decreases beyond $30 \mathrm{mg} / \mathrm{L}$ of dye concentrations. When initial dye concentration increases (beyond $30 \mathrm{mg} / \mathrm{L}$ ), the active sites presented in the adsorbents required for bioadsorption of the dye molecules may be occupied and further adsorption is hindered or prevented by repulsion force of dye or steric hindrance on the adsorbent phase and on the bulk phase $[50,51]$.

3.3.4. Effect of Contact Time. The effect of contact time on the adsorption processes was examined in the range of 10-70 min at optimum values of adsorbent dose $0.2 \mathrm{~g}, \mathrm{pH} 4$ (ALAPW) and $\mathrm{pH} 6$ (RLAPW), initial MG dye concentration 30 and $40 \mathrm{mg} / \mathrm{L}$, and temperature $298 \mathrm{~K}$ with an agitation speed of $200 \mathrm{rpm}$. As shown in Figure 7, MG dye removal efficiency increases with an increase in contact time up to $60 \mathrm{~min}$ and then nearly constant. The results revealed that the adsorption of MG dye onto ALAPW and RLAPW was increased up to $60 \mathrm{~min}$ due to the availability of free/ vacant surface sites of functional groups [52], and nearly constant beyond $60 \mathrm{~min}$ due to the saturation of the available free adsorbing sites or the remaining vacant surface sites are hard to be adsorb due to repulsive forces between the dye molecules on the adsorbents and the bulk phase [50]. Hence, $60 \mathrm{~min}$ was the equilibrium time obtained for MG dye adsorption in this study.

3.3.5. Effect of Temperature. The adsorption process is temperature-dependent [53]. The temperature effect was explained using $298 \mathrm{~K}, 303 \mathrm{~K}, 313 \mathrm{~K}$, and $323 \mathrm{~K}$ at MG dye concentration $30 \mathrm{mg} / \mathrm{L}$, adsorbent dose $0.2 \mathrm{~g}, \mathrm{pH} 4$ (ALAPW) and 6 (RLAPW), and contact time $60 \mathrm{~min}$ with agitation speed $200 \mathrm{rpm}$. Figure 8 shows the removal of MG dye by ALAPW and RLAPW was decreased with increasing 


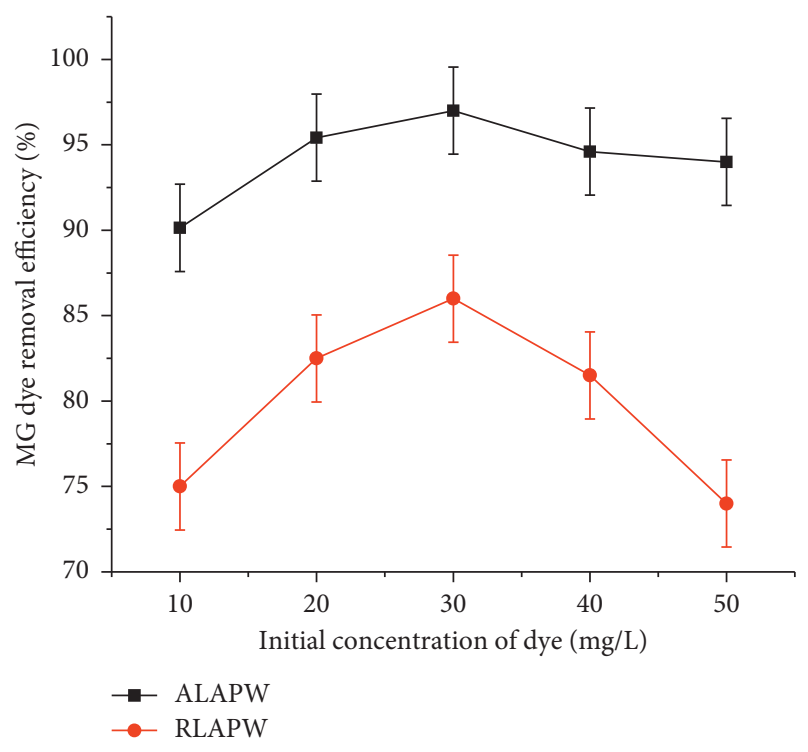

FIgURe 6: Effect of initial MG dye concentration on MG dye removal by ALAPW and RLAPW at pH 4 (ALAPW) and $\mathrm{pH} 6$ (RLAPW), adsorbent dose $0.2 \mathrm{~g}$, contact time $60 \mathrm{~min}$, and temperature $(298 \mathrm{~K})$ with agitation speed $200 \mathrm{rpm}$.

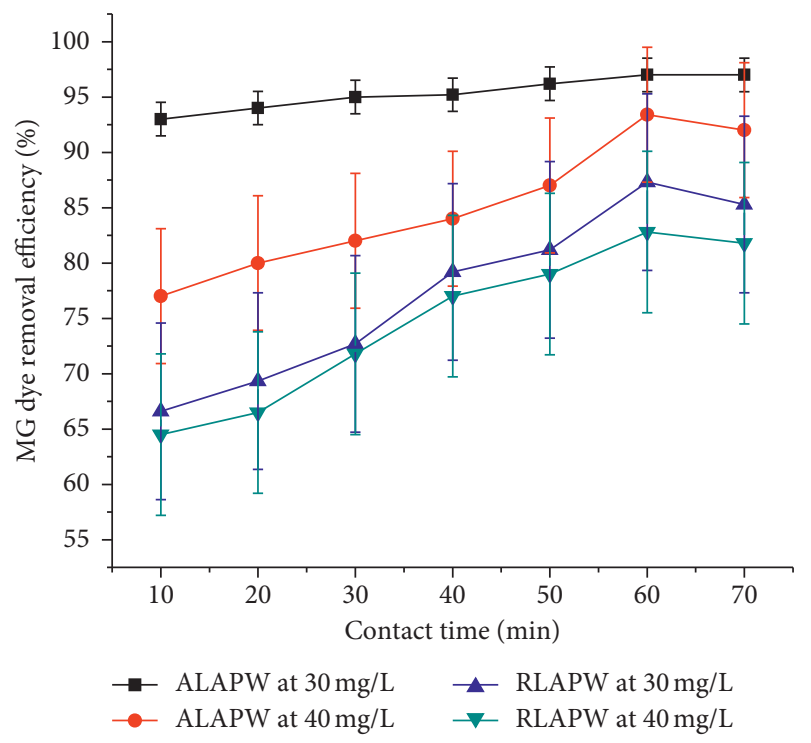

FIgUre 7: Contact time effect on MG dye removal by ALAPW and RLAPW at adsorbent dose $0.2 \mathrm{~g}, \mathrm{pH} 4$ (ALAPW) and $\mathrm{pH} 6$ (RLAPW), initial MG dye concentration 30 and $40 \mathrm{mg} / \mathrm{L}$, and temperature $(298 \mathrm{~K})$ with agitation speed $200 \mathrm{rpm}$.

the temperature from 298 to $323 \mathrm{~K}$. The results clearly suggested that the adsorption of malachite green (MG) dye on to the adsorbents (ALAPW and RLAPW) was favorable at low temperature and exothermic in nature and such effects were explained [44].

3.4. Thermodynamic Study. Thermodynamic study shows the favorability and feasibility of the adsorption process [52]. The values of thermodynamic parameters evaluated for MG

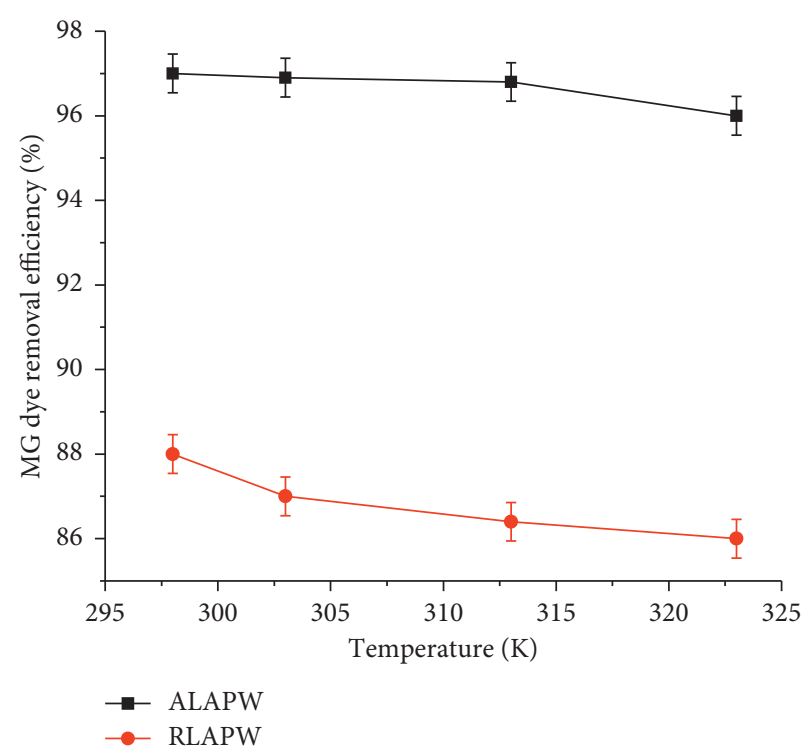

FIgURE 8: Temperature effect on MG dye removal by ALAPW and RLAPW at adsorbent dose $0.2 \mathrm{~g}, \mathrm{pH} 4$ (ALAPW) and $\mathrm{pH} 6$ (RLAPW), initial MG dye concentration $30 \mathrm{mg} / \mathrm{L}$, and contact time 60 min with agitation speed $200 \mathrm{rpm}$.

adsorption onto the adsorbents (RLAPW and RLAPW) such as change in free energy $\left(\Delta G^{\circ}, \mathrm{kJ} \mathrm{mol}^{-1}\right)$, change in enthalpy $\left(\Delta H^{\circ}, \mathrm{kJ} \mathrm{mol}^{-1}\right)$, and change in entropy $\left(\Delta S^{\circ}, \mathrm{kJ} \cdot \mathrm{mol}^{-1} \cdot \mathrm{K}^{-1}\right)$ were determined by the change of equilibrium temperature using the following equations [54]:

$$
\begin{aligned}
\Delta G^{\circ} & =-\operatorname{RTLn}\left(K_{c}\right)=-2.303 \operatorname{RTLog}\left(K_{c}\right), \\
K_{C} & =\frac{q_{e}}{C_{e}}, \\
\Delta G^{\circ} & =\Delta H^{\circ}-T \Delta S^{\circ}, \\
\operatorname{Ln}\left(K_{c}\right) & =-\frac{\Delta H^{\circ}}{\mathrm{RT}}+\frac{\Delta S^{\circ}}{R},
\end{aligned}
$$

where $R(R=8.314 \mathrm{~J} / \mathrm{molK})$ is the universal gas constant, $T$ is the absolute temperature $(\mathrm{K}), q_{e}(\mathrm{mg} / \mathrm{g})$ is the amount of MG dye adsorbed on the RLAPW and ALAPW of the solution at equilibrium, $C_{e}(\mathrm{mg} / \mathrm{L})$ is the equilibrium concentration of the dye in the solution, and $K_{c}\left(q_{e} / C_{e}\right)$ is the thermodynamic equilibrium constant. The values of $\Delta H^{\circ}$ and $\Delta S^{\circ}$ were determined from the slope $\left(-\Delta H^{\circ} / R\right)$ and intercept $\left(\Delta S^{\circ} / R\right)$ of the plot of $\operatorname{Ln}\left(K_{c}\right)$ versus $1 / T$ (Figure 9). As shown in Table 2, the negative $\Delta G^{\circ}$ values indicated spontaneous feasible adsorption process in nature; negative $\Delta H^{\circ}$ values suggested the exothermic nature of the adsorption; and the negative $\Delta S^{\circ}$ values suggest the decrease in adsorbate concentration.

3.5. Kinetic Study. Adsorption kinetics for the adsorbents of ALAPW and RLAPW were conducted at $\mathrm{pH} 4$ (ALAPW) and $\mathrm{pH} 6$ (RLAPW), adsorbent dose $0.2 \mathrm{~g}$, initial MG dye concentration $30 \mathrm{mg} / \mathrm{L}$ and $40 \mathrm{mg} / \mathrm{L}$, contact time $10-70$ minute, and temperature $298 \mathrm{~K}$. The adsorption kinetic 


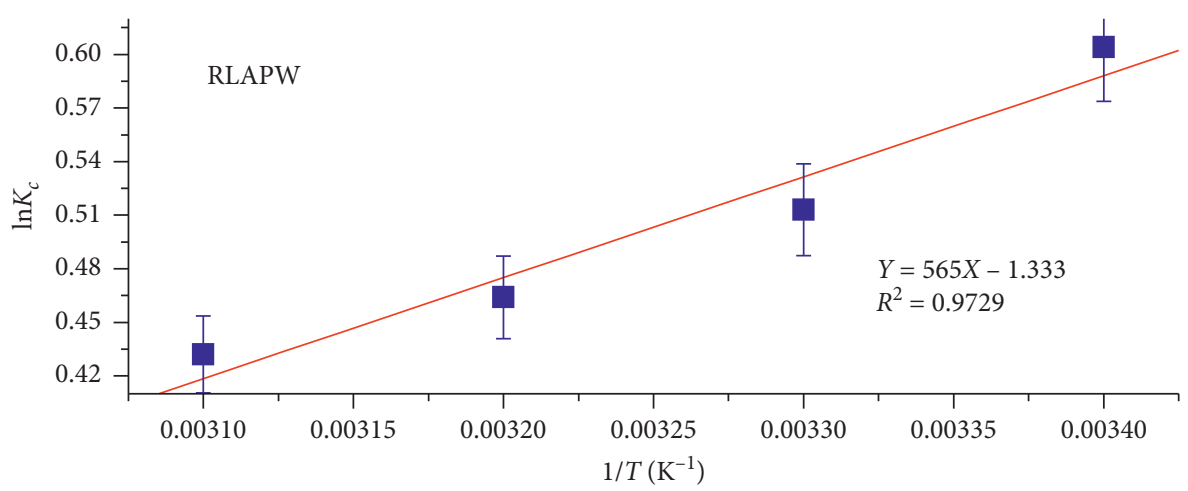

(a)



(b)

FIgURe 9: Plots of $\operatorname{lnKc}$ vs. $1 / T$ for the estimation of thermodynamic parameters.

TABLE 2: The values of thermodynamic parameters.

\begin{tabular}{|c|c|c|c|c|c|c|}
\hline \multirow{2}{*}{ Type of adsorbent } & \multirow{2}{*}{ Temperature (K) } & \multicolumn{5}{|c|}{ Thermodynamic parameters } \\
\hline & & $\ln K_{c}$ & $\Delta G^{\circ}(\mathrm{kJ} / \mathrm{mol})$ & $\Delta H^{\circ}(\mathrm{kJ} / \mathrm{molK})$ & $\Delta S^{\circ}(\mathrm{J} / \mathrm{mol} \mathrm{K})$ & Errors \\
\hline \multirow{4}{*}{ ALAPW } & 298 & 8.083 & -1.395 & \multirow{4}{*}{-4.697} & \multirow{4}{*}{-11.083} & 0.14071 \\
\hline & 303 & 7.815 & -1.339 & & & 0.14071 \\
\hline & 313 & 6.694 & -1.228 & & & 0.14071 \\
\hline & 323 & 6.000 & -1.118 & & & 0.14071 \\
\hline \multirow{4}{*}{ RLAPW } & 298 & 1.830 & -5.200 & \multirow{4}{*}{-8.879} & \multirow{4}{*}{-12.346} & 0.0302 \\
\hline & 303 & 1.67 & -5.139 & & & 0.02565 \\
\hline & 313 & 1.59 & -5.016 & & & 0.0232 \\
\hline & 323 & 1.54 & -4.892 & & & 0.0216 \\
\hline
\end{tabular}

parameters are useful for defining the adsorption rate and give important information on the mechanism of the sorption process $[16,55]$, and the adsorption dynamics was studied by the kinetics in terms of the order of the rate constant [56]. In order to investigate the mechanism of dye adsorption onto RLAPW and ALAPW, adsorption kinetics was studied using the pseudo-first-order (equation (9)), pseudo-second-order (equation (10)), and intraparticle diffusion model (equation (11)), respectively [46, 52].

$$
\begin{aligned}
\log \left(q_{e}-q_{t}\right) & =\log q_{e}-k_{1} t \\
\frac{t}{q_{t}} & =\frac{1}{k_{2} q_{e}^{2}}+\frac{t}{q_{e}}
\end{aligned}
$$

$$
q_{t}=k_{\mathrm{diff}} t^{1 / 2}+C
$$

where $q_{t}$ is amount adsorbed at time $t(\mathrm{mg} / \mathrm{g}), q_{e}$ is amount adsorbed at equilibrium time $(\mathrm{mg} / \mathrm{g}), k_{1}$ is the pseudo-firstorder rate constant $\left(\mathrm{min}^{-1}\right), k_{2}$ is the pseudo-second-order rate constant $(\mathrm{g} / \mathrm{mg} \cdot \mathrm{min}), k_{\text {diff }}$ is the intraparticle diffusion rate constant $\left(\mathrm{mg} / \mathrm{g} \cdot \mathrm{min}^{1 / 2}\right)$, and $C$ is the intercept. The kinetic parameters (Table 3) for each model were calculated by plotting graph $\log \left(q_{e}-q_{t}\right)$ vs. $t$ for pseudo-first-order, $t / q_{t}$ vs. $t$ for pseudo-second-order (Figure 10), and $q_{t}$ vs. $t^{1 / 2}$ for intraparticle diffusion models (Figure 11).

It was observed that, for the pseudo-first-order and intraparticle diffusion model of MG dye adsorption, $R^{2}$ was relatively low and the calculated $q_{e}\left(q_{e}\right.$ calc. $)$ value was 
TABLE 3: Kinetic parameters for MG adsorption onto ALAPW and RLAPW adsorbents.

\begin{tabular}{|c|c|c|c|c|c|}
\hline \multirow{4}{*}{ Kinetics } & \multirow{4}{*}{$\begin{array}{c}\text { Parameters } \\
q_{e} \text { exp.(mg/g) }\end{array}$} & \multicolumn{3}{|c|}{ ALAPW } & \multirow[t]{2}{*}{ RLAPW } \\
\hline & & \multicolumn{3}{|c|}{ Concentration $(\mathrm{mg} / \mathrm{L})$} & \\
\hline & & 30 & 40 & 30 & 40 \\
\hline & & 7.27 & 9.38 & 6.55 & 8.30 \\
\hline \multirow{3}{*}{ Pseudo-first order } & $R^{2}$ & 0.98054 & 0.81356 & 0.99334 & 0.97849 \\
\hline & $k_{1}\left(\min ^{-1}\right)$ & -0.0145 & -0.0259 & -0.00906 & -0.0178 \\
\hline & $q_{e}$ cal. $(\mathrm{mg} / \mathrm{g})$ & 0.414 & 20.845 & 1.975 & 3.296 \\
\hline \multirow{3}{*}{ Pseudo-second order } & $R^{2}$ & 0.99994 & 0.99901 & 0.9991 & 0.99762 \\
\hline & $q_{\mathrm{e}}$ cal. $(\mathrm{mg} / \mathrm{g})$ & 7.396 & 8.475 & 6.163 & 8.948 \\
\hline & $k_{2}(\mathrm{~g} / \mathrm{mg} \cdot \mathrm{min})$ & 0.00033 & 0.03463 & 0.05193 & 0.02365 \\
\hline \multirow{3}{*}{ Intraparticle diffusion model } & $R^{2}$ & 0.98872 & 0.93944 & 0.95584 & 0.97933 \\
\hline & $k_{\text {diff }}\left(\mathrm{mg} / \mathrm{g} \cdot \mathrm{min}^{1 / 2}\right)$ & 0.05791 & 0.51419 & 0.29979 & 0.38931 \\
\hline & $C(\mathrm{mg} / \mathrm{g})$ & 6.79576 & 4.81571 & 3.91344 & 5.11084 \\
\hline
\end{tabular}

dramatically lower than the experimental $q_{e}\left(q_{e}\right.$ exp.) value. However, the pseudo-second-order kinetic model provided a near perfect match between the calculated ( $q_{e}$ calc.) and experimental ( $q_{e}$ exp.) values, and its $R^{2}$ value is close to unity for both adsorbents. As a result, the adsorption of MG dye on both adsorbents fitted well into the pseudo-secondorder kinetic model.

3.6. Adsorption Isotherms. Equilibrium adsorption isotherms were studied with $\mathrm{MG}$ dye concentrations (10-50 mg/L) with a fixed adsorbent mass (0.2 g), $\mathrm{pH} 4$ (ALAPW) and 6 (RLAPW), contact time $60 \mathrm{~min}$, and temperature $298 \mathrm{~K}$. In this study, the adsorption of MG dye onto ALAPW and RLAPW was analyzed by various isotherm models such as Langmuir, Freundlich, Redlich-Peterson, and Sips isotherms. The Langmuir model assumes the formation of a monolayer of adsorbate on the outer surface of the adsorbent (uniform energies of adsorption) and no further adsorption thereafter (applicable to homogeneous sorption or all sorption sites are identical) and expressed by equation (12) [46].

$$
\frac{C_{e}}{q_{e}}=\frac{1}{b q_{m}}+\frac{C_{e}}{q_{m}},
$$

where $C_{e}(\mathrm{mg} / \mathrm{L})$ is the equilibrium solute concentration of dye in solution, $q_{e}(\mathrm{mg} / \mathrm{g})$ is the adsorbed value of dye at equilibrium concentration, $q_{m}(\mathrm{mg} / \mathrm{g})$ is the maximum monolayer adsorption capacity, and $b$ is the Langmuir adsorption constant $(\mathrm{L} / \mathrm{mg})$. Slope $\left(1 / q_{m}\right)$ and intercept $\left(1 / b q_{m}\right)$ of the straight line plot of $C_{e} / q_{e}$ versus $C_{e}$ is shown in Figure 12. The values of Langmuir isotherm constants $q_{m}$ and $b$ are presented in Table 4 .

The type of the Langmuir isotherm could be predicted based on whether the adsorption was favorable or unfavorable in terms of equilibrium parameter or dimensionless constant separation factor $R_{L}$ [45], which is presented as follows:

$$
R_{L}=\frac{1}{1+b C_{o}}
$$

where $R_{L}$ is the Langmuir constant and $C_{o}$ is the initial concentration of adsorbate. The values of $R_{L}$ indicates whether the isotherm is unfavorable $\left(R_{L}>1\right)$, linear $\left(R_{L}=1\right)$, favorable $\left(R_{L}<1\right)$, or irreversible $\left(R_{L}=0\right)$. As shown in Table 5, the values of $R_{L}$ (between 0 and 1) indicate that the isotherm was favorable.

Freundlich isotherm is used to describe the adsorption surface becoming heterogeneous (nonuniform) during the adsorption process [45] and expressed in

$$
\log q_{e}=\log k_{f}+\frac{\log C_{e}}{n},
$$

where $C_{e}$ is the equilibrium concentration of dye in solution $(\mathrm{mg} / \mathrm{L}), q_{e}$ is the adsorbed value of dye at equilibrium concentration $(\mathrm{mg} / \mathrm{g})$, and $K_{f}$ and $n$ are Freundlich constants characteristics of the system, indicating the adsorption capacity and the adsorption intensity. The Freundlich coefficients, $K_{f}$ (related to adsorption capacity) and $n$ (related to adsorption intensity), obtained from the slope $(1 / n)$ and the intercept $\left(\log K_{f}\right)$ of the linearized plots of $\log q_{e}$ versus $\log$ $C_{e}$ (Figure 12) are shown in Table 4 . The value $n>1$ suggests that adsorbate is favorably adsorbed on the adsorbent. The higher the $n$ value is, the stronger the adsorption intensity is [13].

The Sips isotherm model is a combination of both Langmuir and Freundlich isotherm, and the model is valid for localized adsorption without adsorbate-adsorbate interactions $[57,58]$. This model is also used for predicting the heterogeneous adsorption systems and circumventing the limitation of the rising adsorbate concentration associated with the Freundlich isotherm model. At the low adsorbate concentrations (at low $C_{e}$ ), the Sips isotherm model effectively reduces to the Freundlich isotherm, and at high adsorbate concentrations (at high $C_{e}$ ), this model predicts a monolayer sorption capacity characteristic of the Langmuir isotherm. The Sips isotherm model is expressed in

$$
\frac{1}{q_{e}}=\frac{1}{Q_{\max } K_{s}}\left(\frac{1}{C_{e}}\right)^{1 / n}+\frac{1}{Q_{\max }},
$$

where $K_{s}(\mathrm{~L} / \mathrm{mg})$ is the Sips equilibrium constant and $Q_{\max }$ $(\mathrm{mg} / \mathrm{g})$ is maximum adsorption capacity values obtained from the slope and the intercept of the plot as shown in Figure 13. The Sips isotherm equation is characterized by the dimensionless heterogeneity factor, $n$, which can also be 



FIgURe 10: Pseudo-first-order (a) for ALAPW and (b) for RLAPW and pseudo-second-order (c) for ALAPW and (d) for RLAPW for the adsorption of MG dye at different contact time intervals.
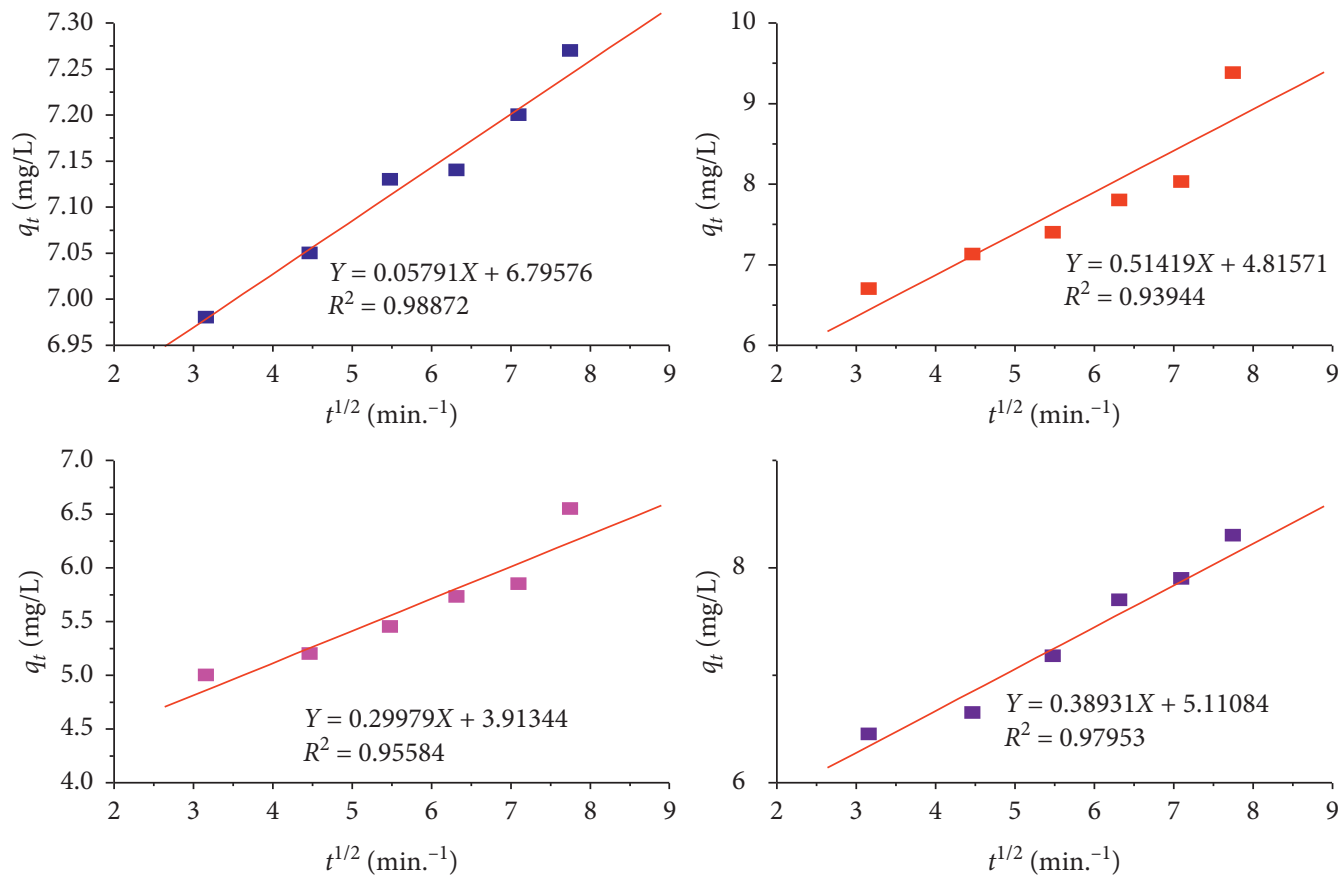

Figure 11: Intraparticle diffusion model (a) for ALAPW and (b) for RLAPW at different contact times (10-70 min). 

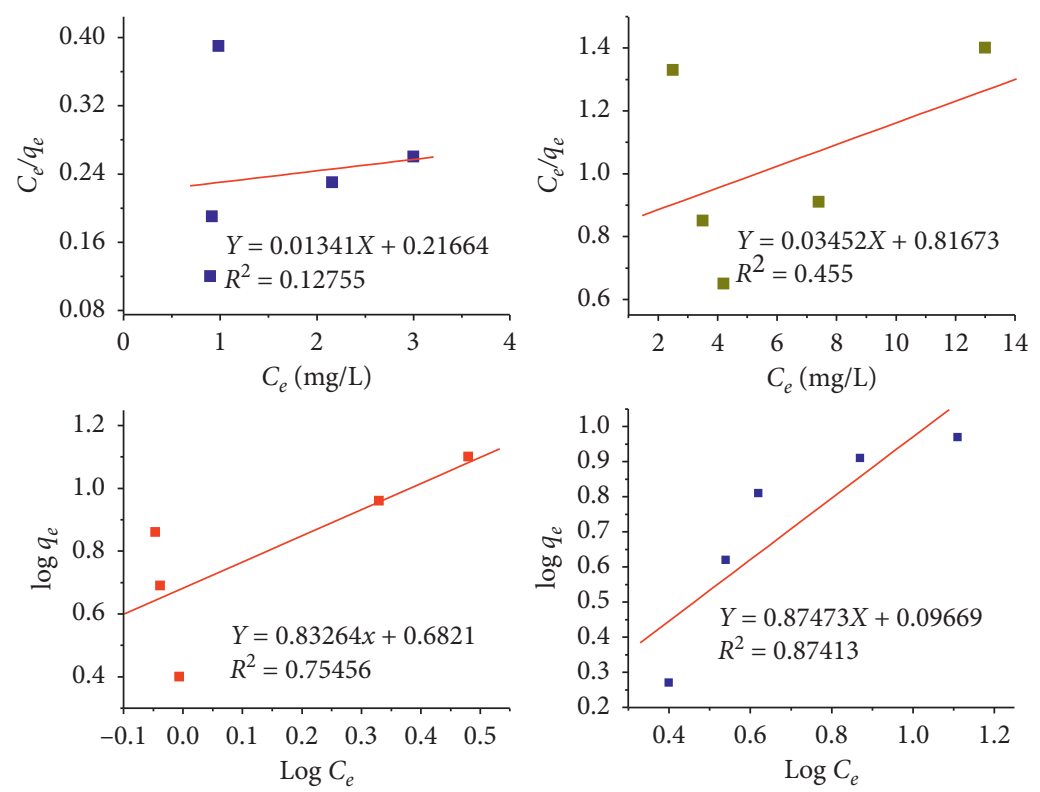

Figure 12: Langmuir isotherm (a) for ALAPW and (b) for RLAPW and Freundlich isotherm (c) for ALAPW and (d) RLAPW.

TABLE 4: Isotherm parameters for the adsorption of MG dye onto ALAPW and RLAPW.

\begin{tabular}{lccc}
\hline Isotherm models & Parameters & ALAPW & RLAPW \\
\hline \multirow{4}{*}{ Langmuir } & $R^{2}$ & 0.12755 & 0.455 \\
& $q_{m}(\mathrm{mg} / \mathrm{g})$ & 74.6 & 29.0 \\
& $b(\mathrm{~L} / \mathrm{mg})$ & 0.062 & 0.042 \\
Freundlich & $R^{2}$ & 0.75456 & 0.87413 \\
& $K_{f}(\mathrm{mg} / \mathrm{g})$ & 4.81 & 1.25 \\
& $n$ & 1.21 & 1.14 \\
Sips & $Q_{\max } \cdot(\mathrm{mg} / \mathrm{g})$ & 36.14 & 19.43 \\
& $K_{s}(\mathrm{~L} / \mathrm{mg})$ & 1.4 & 0.05 \\
& $n$ & 1 & 1 \\
Redlich-Peterson & $R^{2}$ & 0.59014 & 0.9022 \\
& $\beta$ & 0.21796 & 0.13014 \\
& $A(\mathrm{mg} / \mathrm{L})$ & 38.05 & 1.68 \\
& $R^{2}$ & 0.28381 & 0.26368 \\
\hline
\end{tabular}

TABLE 5: $R_{L}$ (dimensionless constant separation factor) values at different initial concentration.

\begin{tabular}{lcccccc}
\hline \multirow{2}{*}{ Adsorbent } & & \multicolumn{5}{c}{$R_{L}$ values } \\
& & \multicolumn{5}{c}{ Concentration $(\mathrm{mg} / \mathrm{L})$} \\
& & 10 & 20 & 30 & 40 & 50 \\
\hline ALAPW & $0.2 \mathrm{~g}$ & 0.62 & 0.45 & 0.35 & 0.29 & 0.24 \\
RLAPW & $0.2 \mathrm{~g}$ & 0.70 & 0.54 & 0.44 & 0.37 & 0.32 \\
\hline
\end{tabular}

employed to describe the system's heterogeneity when $n$ is between 0 and 1 . When $n=1$, the Sips equation reduces to the Langmuir equation, and it implies a homogeneous adsorption process.

Redlich-Peterson isotherm is a hybrid isotherm featuring both Langmuir and Freundlich isotherms, which incorporate three parameters into an empirical equation which may be used to represent adsorption equilibria over a wide concentration range and can be applied either in homogeneous or heterogeneous systems due to its versatility
[57]. The linear form of the Redlich-Peterson isotherm is represented by

$$
\ln \frac{C_{e}}{q_{e}}=\beta \ln C_{e}-\ln A,
$$

where $\ln A$ is the Redlich-Peterson isotherm constant obtained from the intercept of $\ln \left(C_{e} / q_{e}\right)$ versus $\ln \mathrm{C}_{e}$ graphs and $\beta$ is the exponent between 0 and 1 . The experimental data analyzed by Sips and Redlich-Peterson isotherms are shown in Figure 13.

Isotherm parameters and correlation factor $\left(R^{2}\right)$ for both models are presented in Table 4 . The results revealed that the Freundlich isotherm correlation factor for ALAPW relatively close to unity confirms Freundlich isotherm model which better describes the interaction between adsorbent and adsorbate in the aqueous system. For RLAPW, the Sips isotherm correlation factor close to unity better describes the interaction between adsorbent and adsorbate in the aqueous system.

Dimensionless constant separation factor $\left(R_{L}\right)$ value indicates the adsorption nature to be either favorable if $0<R_{L}<1$, unfavorable if $R_{L}>1$, linear if $R_{L}=1$, and irreversible if $R_{L}=0$ [59]. For this study, all the $R_{L}$ valves were obtained between 0 and 1 which confirming that the adsorption of MG dye over the ALAPW and RLAPW was favorable [59]. In the present study, the calculated $R_{L}$ values for the adsorption of MG on ALAPW and RLAPW adsorbents are presented in Table 5 at initial concentrations of 10, 20, 30, 40, and $50 \mathrm{mg} / \mathrm{L}$. These $R_{L}$ values confirmed that adsorbents (ALAPW and RLAPW) are favorable for adsorbing MG dye from aqueous solution under the conditions applied in this study.

3.7. Desorption Study. High desorption efficiency and good reusability after adsorption are desirable for an adsorbents. Desorption studies are helpful to explain the nature of 

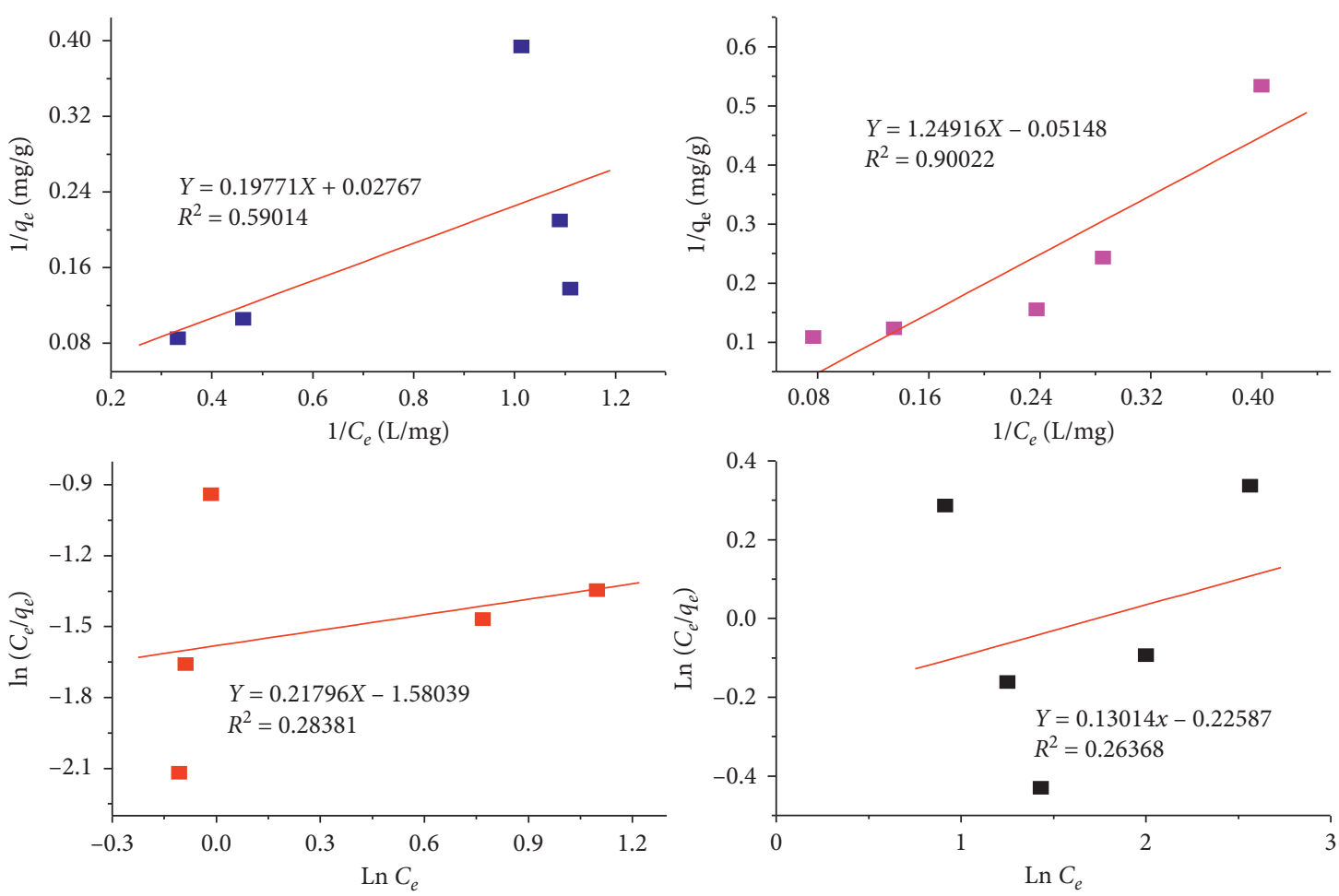

Figure 13: Sips isotherm (a) for ALAPW and (b) for RLAPW, Redlich-Peterson isotherm (c) for ALAPW and (d) RLAPW.

adsorption and recycling of the spent adsorbent and the dye [51, 60-63]. The regeneration of ALAPW and RLAPW was conducted by immersing the adsorbents into different solvents $\mathrm{Me}-\mathrm{OH}(99 \%), \mathrm{NaOH}(0.1 \mathrm{M})$, and $\mathrm{HCl}(0.1 \mathrm{M})$, and the results are presented in Figure 14. As shown in Figure 14, the regeneration of adsorbents by $0.1 \mathrm{M} \mathrm{NaOH}$ was more efficient (compared to the other solvents). These phenomena are consistent with the results observed for the effect of $\mathrm{pH}$. Since the maximum removal efficiency of MG is attained at weakly acidic conditions, it is expectable that desorption is favored at high $\mathrm{pH}$ values. At $\mathrm{pH} 2$, a significantly high electrostatic repulsion exists between the positively charged surfaces of both adsorbents and the cationic MG dye so that regeneration is carried out as a result of charge competition. As described in the figure, ALAPW has high regeneration ability as compared to RLAPW. This is because the high fixed carbon of the activated carbon gives a better strength and porosity nature. Therefore, ALAPW shows excellent adsorption performance and regeneration, and its use can be extended to environmental applications for wastewater treatment.

3.8. Proposed Adsorption Mechanism. The bioadsorption of MG dye from aqueous solutions by RLAPW and ALAPW is strongly dependent on the various polar functional groups on the surface of the adsorbents such as hydroxyl (cellulose, pectin, hemicellulose, adsorbed water, and lignin), phenols, amines, and aromatics, which are supported by FTIR spectral results described in Figure 3. The surface functional groups of the adsorbents may be charged, neutral upon protonation/deprotonation, and multiple bonded upon

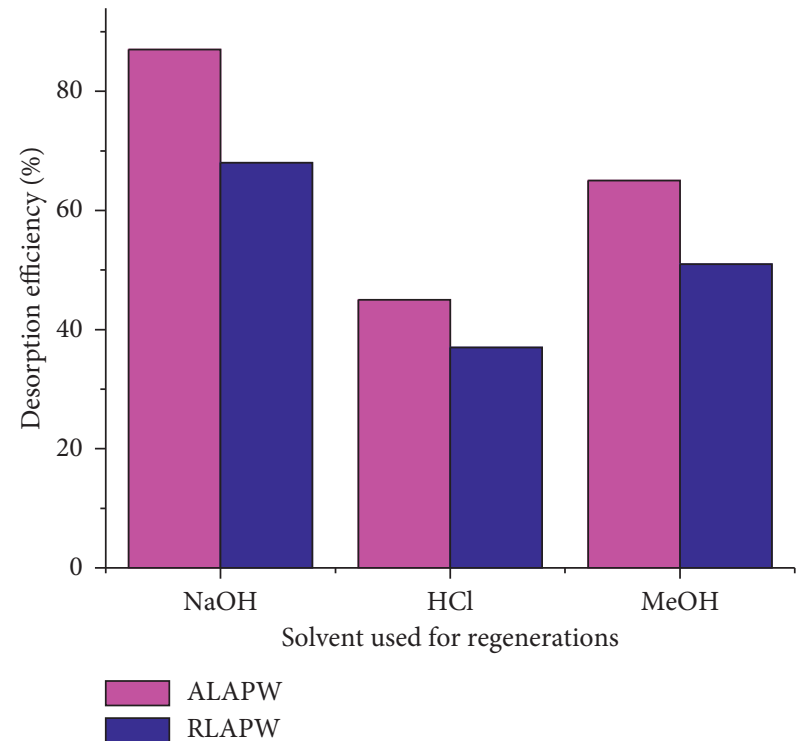

Figure 14: Desorption efficiency (\%) using different solvent solutions.

delocalization. The possible adsorption mechanism of MG dye on the adsorbents surface is summarized in Figure 15. The probable adsorption mechanisms between the adsorbents surface functional groups and MG dye can be related to the various interactions such as electrostatic attractions, hydrogen bonding interaction, and $\pi-\pi$ interactions [38]. Similar observation was reported for the adsorption on MG on chemically modified rice husk [64]. The comparison of 




Figure 15: Possible adsorption mechanisms between LAPW and MG dye.

TABle 6: Previously reported adsorption capacities of various wastes for MG dye removal.

\begin{tabular}{lccc}
\hline Adsorbents & PH & $\begin{array}{c}\text { Capacity } \\
(\mathrm{mg} / \mathrm{g})\end{array}$ & References \\
\hline Wood apple shell & 7.5 & 34.56 & {$[53]$} \\
Neem sawdust & 7.2 & 4.35 & {$[65]$} \\
Tamarind fruit shell & 5 & 1.95 & {$[66]$} \\
Cellulose powder & 7.2 & 2.42 & {$[67]$} \\
Avena sativa hull & 8 & 83 & {$[68]$} \\
Arunda donax root & 5 & 8.7 & {$[69]$} \\
carbon & & & \\
Rice husk $\left(\mathrm{HNO}_{3}{ }^{-}\right.$ & 8 & 18.1 & {$[70]$} \\
treated) & & & \\
Saw dust (NaOH- & 2.9 & 58.479 & {$[70]$} \\
treated) & & & \\
Prosopis cineraria & 6 & 65.8 & {$[70]$} \\
sawdust & 7 & 52.91 & {$[70]$} \\
Pine needles & Ambient & 90.8 & {$[71]$} \\
Walnut shell & 4 & 25.6 & {$[72]$} \\
Modified rice straw & 6 & 81.5 & {$[73]$} \\
Maize husk leaf & Natural & 6.2 & {$[74]$} \\
Waste pea shells & 4 & 7.3 & This study \\
ALAPW & 6 & 6.6 & This study \\
RLAPW & & &
\end{tabular}

previously reported adsorption capacities of various wastes for MG dye removal is presented in Table 6.

\section{Conclusion}

This study proposed to use a naturally available, noncost, and environmental friendly Lupinus albus seed peel waste as a novel adsorbent to remove malachite green dye for the first time. The effects of experimental parameters such as $\mathrm{pH}$, adsorbent dose, initial dye concentration, contact time, and temperature on the percentage of MG dye removal were investigated. The best fit adsorption isotherm models for RLAPW and ALAPW were Freundlich and Sips with the adsorption capacity of $6.6 \mathrm{mg} / \mathrm{g}$ and $7.3 \mathrm{mg} / \mathrm{g}$, respectively. The best fit kinetic model for both adsorbents was pseudosecond-order. The thermodynamics parameters indicated that the adsorption was spontaneous and exothermic in nature. Desorption studies were conducted, and the results showed that the adsorbents have regeneration ability at acidic $\mathrm{pH}$ 2. This study provides a good indication that the prepared adsorbents are an efficient adsorbent for the removal of dyes from aqueous solution.

\section{Abbreviations}

ALAPW: Activated Lupinus albus peel waste

RLAPW: Raw Lupinus albus peel waste

LAPW: Lupinus albus peel waste

FTIR: Fourier transform infrared spectroscopy

MG: Malachite green

pHzpc: Point of zero charge.

\section{Data Availability}

The data used to support the findings of this study are included within the article.

\section{Conflicts of Interest}

The authors declare that there are no conflicts of interest.

\section{Authors' Contributions}

The authors contributed to experimental activities, manuscript writing, and editing and approved the final manuscript. 


\section{Acknowledgments}

The authors express their appreciation to the Department of Chemistry, Woldia University and Bahir Dar, Ethiopia, for material support.

\section{References}

[1] V. S. Munagapati, V. Yarramuthi, Y. Kim, K. M. Lee, and D.-S. Kim, "Removal of anionic dyes (reactive black 5 and congo red) from aqueous solutions using banana peel powder as an adsorbent," Ecotoxicology and Environmental Safety, vol. 148, pp. 601-607, 2018.

[2] N. K. Mondal and S. Kar, "Potentiality of banana peel for removal of congo red dye from aqueous solution: isotherm, kinetics and thermodynamics studies," Applied Water Science, vol. 8, no. 6, p. 157, 2018.

[3] M. T. Uddin, M. A. Rahman, M. Rukanuzzaman, and M. A. Islam, "A potential low cost adsorbent for the removal of cationic dyes from aqueous solutions," Applied Water Science, vol. 7, no. 6, pp. 2831-2842, 2017.

[4] I. Anastopoulos and G. Z. Kyzas, "Agricultural peels for dye adsorption: a review of recent literature," Journal of Molecular Liquids, vol. 200, pp. 381-389, 2014.

[5] L. Ai, C. Zhang, F. Liao et al., "Removal of methylene blue from aqueous solution with magnetite loaded multi-wall carbon nanotube: kinetic, isotherm and mechanism analysis," Journal of Hazardous Materials, vol. 198, pp. 282-290, 2011.

[6] L. G. T. Dos Reis, N. F. Robaina, W. F. Pacheco, and R. J. Cassella, "Separation of malachite green and methyl green cationic dyes from aqueous medium by adsorption on amberlite XAD-2 and XAD-4 resins using sodium dodecylsulfate as carrier," Chemical Engineering Journal, vol. 171, no. 2, pp. 532-540, 2011.

[7] J. Georgin, B. da Silva Marques, J. da Silveira Salla, E. L. Foletto, D. Allasia, and G. L. Dotto, "Removal of procion red dye from colored effluents using $\mathrm{H}_{2} \mathrm{SO}_{4}-/ \mathrm{HNO}_{3}$-treated avocado shells (Persea americana) as adsorbent," Environmental Science and Pollution Research, vol. 25, no. 7, pp. 6429-6442, 2018.

[8] N. P. Raval, P. U. Shah, and N. K. Shah, "Nanoparticles loaded biopolymer as effective adsorbent for adsorptive removal of malachite green from aqueous solution," Water Conservation Science and Engineering, vol. 1, no. 1, pp. 69-81, 2016.

[9] A. A. Yakout and M. A. Shaker, "Dodecyl sulphate functionalized magnetic graphene oxide nanosorbent for the investigation of fast and efficient removal of aqueous malachite green," Journal of the Taiwan Institute of Chemical Engineers, vol. 63, pp. 81-88, 2016.

[10] L. Zhang, H. Zhang, W. Guo, and Y. Tian, "Removal of malachite green and crystal violet cationic dyes from aqueous solution using activated sintering process red mud," Applied Clay Science, vol. 93-94, pp. 85-93, 2014.

[11] H. Shayesteh, A. Rahbar-Kelishami, and R. Norouzbeigi, "Adsorption of malachite green and crystal violet cationic dyes from aqueous solution using pumice stone as a low-cost adsorbent: kinetic, equilibrium, and thermodynamic studies," Desalination and Water Treatment, vol. 57, no. 27, pp. 12822-12831, 2016.

[12] M. A. Ahmad, N. A. Ahmad Puad, and O. S. Bello, "Kinetic, equilibrium and thermodynamic studies of synthetic dye removal using pomegranate peel activated carbon prepared by microwave-induced $\mathrm{KOH}$ activation," Water Resources and Industry, vol. 6, pp. 18-35, 2014.
[13] M. A. Ahmad and R. Alrozi, "Removal of malachite green dye from aqueous solution using rambutan peel-based activated carbon: equilibrium, kinetic and thermodynamic studies," Chemical Engineering Journal, vol. 171, no. 2, pp. 510-516, 2011.

[14] M. E. Fernandez, G. V. Nunell, P. R. Bonelli, and A. L. Cukierman, "Activated carbon developed from orange peels: batch and dynamic competitive adsorption of basic dyes," Industrial Crops and Products, vol. 62, pp. 437-445, 2014.

[15] A. Asfaram, M. R. Fathi, S. Khodadoust, and M. Naraki, "Removal of direct red 12B by garlic peel as a cheap adsorbent: kinetics, thermodynamic and equilibrium isotherms study of removal," Spectrochimica Acta Part A: Molecular and Biomolecular Spectroscopy, vol. 127, pp. 415-421, 2014.

[16] L. Y. Lee, S. Gan, M. S. Yin Tan, S. S. Lim, X. J. Lee, and Y. F. Lam, "Effective removal of acid blue 113 dye using overripe Cucumis sativus peel as an eco-friendly biosorbent from agricultural residue," Journal of Cleaner Production, vol. 113, pp. 194-203, 2016.

[17] S. Shakoor and A. Nasar, "Removal of methylene blue dye from artificially contaminated water using citrus limetta peel waste as a very low cost adsorbent," Journal of the Taiwan Institute of Chemical Engineers, vol. 66, pp. 154-163, 2016.

[18] F. A. Pavan, A. C. Mazzocato, and Y. Gushikem, "Removal of methylene blue dye from aqueous solutions by adsorption using yellow passion fruit peel as adsorbent," Bioresource Technology, vol. 99, no. 8, pp. 3162-3165, 2008.

[19] M. E. Argun, D. Güclü, and M. Karatas, "Adsorption of reactive blue 114 dye by using a new adsorbent: pomelo peel," Journal of Industrial and Engineering Chemistry, vol. 20, no. 3, pp. 1079-1084, 2014.

[20] M. A. Ahmad, N. S. Afandi, and O. S. Bello, "Optimization of process variables by response surface methodology for malachite green dye removal using lime peel activated carbon," Applied Water Science, vol. 7, no. 2, pp. 717-727, 2017.

[21] S. Saroj, S. V. Singh, and D. Mohan, "Removal of colour (direct blue 199) from carpet industry wastewater using different biosorbents (maize cob, citrus peel and rice husk)," Arabian Journal for Science and Engineering, vol. 40, no. 6, pp. 1553-1564, 2015.

[22] S. Guiza, "Biosorption of heavy metal from aqueous solution using cellulosic waste orange peel," Ecological Engineering, vol. 99, pp. 134-140, 2017.

[23] E. Hoseinzadeh, "Removal of acid dyes from aqueous solution using potato peel waste biomass: a kinetic and equilibrium study," Desalination and Water Treatment, vol. 52, no. 25-27, pp. 4999-5006, 2014.

[24] T. A. Khan, M. Nazir, and E. A. Khan, "Adsorptive removal of rhodamine B from textile wastewater using water chestnut (Trapa natans L.) peel: adsorption dynamics and kinetic studies," Toxicological \& Environmental Chemistry, vol. 95, no. 6, pp. 919-931, 2013.

[25] R. Dod, G. Banerjee, and S. Saini, “Adsorption of methylene blue using green pea peels (Pisum sativum): a cost-effective option for dye-based wastewater treatment," Biotechnology and Bioprocess Engineering, vol. 17, no. 4, pp. 862-874, 2012.

[26] S. Bağc1 and A. A. Ceyhan, "Adsorption of methylene blue onto activated carbon prepared from Lupinus albus," Chemical Industry and Chemical Engineering Quarterly, vol. 22, no. 2, pp. 155-165, 2016.

[27] O. S. Bello, K. A. Adegoke, and O. O. Akinyunni, "Preparation and characterization of a novel adsorbent from Moringa oleifera leaf," Applied Water Science, vol. 7, no. 3, pp. 1295-1305, 2017. 
[28] F. Marrakchi, M. J. Ahmed, W. A. Khanday, M. Asif, and B. H. Hameed, "Mesoporous-activated carbon prepared from chitosan flakes via single-step sodium hydroxide activation for the adsorption of methylene blue," International Journal of Biological Macromolecules, vol. 98, pp. 233-239, 2017.

[29] Y. L. Tan, M. A. Islam, M. Asif, and B. H. Hameed, “Adsorption of carbon dioxide by sodium hydroxide-modified granular coconut shell activated carbon in a fixed bed," Energy, vol. 77, pp. 926-931, 2014.

[30] M. A. Islam, A. Benhouria, M. Asif, and B. H. Hameed, "Methylene blue adsorption on factory-rejected tea activated carbon prepared by conjunction of hydrothermal carbonization and sodium hydroxide activation processes," Journal of the Taiwan Institute of Chemical Engineers, vol. 52, pp. 57-64, 2015.

[31] F. Ahmad, W. M. A. W. Daud, M. A. Ahmad, and R. Radzi, "The effects of acid leaching on porosity and surface functional groups of cocoa (Theobroma cacao)-shell based activated carbon," Chemical Engineering Research and Design, vol. 91, no. 6, pp. 1028-1038, 2013.

[32] V. Viena and M. Nizar, "Characterization of activated carbon prepared from banana peels: effect of chemical activators on the adsorption of gas emissions," Journal of Physics: Conference Series, vol. 1232, Article ID 012005, 2019.

[33] J. Fito, "Fluoride removal from aqueous solution onto activated carbon of Catha edulis through the adsorption treatment technology," Environmental Systems Research, vol. 8, no. 1, p. 25, 2019.

[34] S. Mopoung, P. Moonsri, W. Palas, and S. Khumpai, "Characterization and properties of activated carbon prepared from tamarind seeds by $\mathrm{KOH}$ activation for Fe (III) adsorption from aqueous solution," The Scientific World Journal, vol. 2015, Article ID 415961, 9 pages, 2015.

[35] H. Dargo, N. Gabbiye, and A. Ayalew, "Removal of methylene blue dye from textile wastewater using activated carbon prepared from rice husk," International Journal of Innovation and Scientific Research, vol. 9, no. 2, pp. 317-325, 2014.

[36] D. Kibami, "Preparation and characterization of activated carbon from Fagopyrum esculentum Moench by $\mathrm{HNO}_{3}$ and $\mathrm{H}_{3} \mathrm{PO}_{4}$ chemical activation," Der Chemica Sinica, vol. 5, no. 4, pp. 46-55, 2014.

[37] O. S. Bello and M. A. Ahmad, "Coconut (Cocos nucifera) shell based activated carbon for the removal of malachite green dye from aqueous solutions," Separation Science and Technology, vol. 47, no. 6, pp. 903-912, 2012.

[38] A. H. Jawad, R. Razuan, J. N. Appaturi, and L. D. Wilson, "Adsorption and mechanism study for methylene blue dye removal with carbonized watermelon (Citrullus lanatus) rind prepared via one-step liquid phase $\mathrm{H}_{2} \mathrm{SO}_{4}$ activation," Surfaces and Interfaces, vol. 16, pp. 76-84, 2019.

[39] A. Ahmad, M. Rafatullah, O. Sulaiman, M. H. Ibrahim, and R. Hashim, "Scavenging behaviour of meranti sawdust in the removal of methylene blue from aqueous solution," Journal of Hazardous Materials, vol. 170, no. 1, pp. 357-365, 2009.

[40] M. Ghaedi, H. Tavallali, M. Sharifi, S. N. Kokhdan, and A. Asghari, "Preparation of low cost activated carbon from Myrtus communis and pomegranate and their efficient application for removal of congo red from aqueous solution," Spectrochimica Acta Part A: Molecular and Biomolecular Spectroscopy, vol. 86, pp. 107-114, 2012.

[41] V. S. Munagapati, J.-C. Wen, C.-L. Pan, Y. Gutha, J.-H. Wen, and G. M. Reddy, "Adsorptive removal of anionic dye (reactive black 5) from aqueous solution using chemically modified banana peel powder: kinetic, isotherm, thermodynamic, and reusability studies," International Journal of Phytoremediation, vol. 22, no. 3, pp. 267-278, 2020.

[42] Y. Li, Q. Du, T. Liu et al., "Comparative study of methylene blue dye adsorption onto activated carbon, graphene oxide, and carbon nanotubes," Chemical Engineering Research and Design, vol. 91, no. 2, pp. 361-368, 2013.

[43] F. Temesgen, N. Gabbiye, and O. Sahu, "Biosorption of reactive red dye (RRD) on activated surface of banana and orange peels: economical alternative for textile effluent," Surfaces and Interfaces, vol. 12, pp. 151-159, 2018.

[44] A. K. Kushwaha, N. Gupta, and M. C. Chattopadhyaya, "Removal of cationic methylene blue and malachite green dyes from aqueous solution by waste materials of Daucus carota," Journal of Saudi Chemical Society, vol. 18, no. 3, pp. 200-207, 2014.

[45] V. S. Munagapati and D.-S. Kim, "Adsorption of anionic azo dye congo red from aqueous solution by cationic modified orange peel powder," Journal of Molecular Liquids, vol. 220, pp. 540-548, 2016.

[46] N. A. Rahmat, "Removal of remazol brilliant blue R from aqueous solution by adsorption using pineapple leaf powder and lime peel powder," Water, Air, \& Soil Pollution, vol. 227, no. 4 , p. 105, 2016.

[47] M. Ghaedi, A. G. Nasab, S. Khodadoust, M. Rajabi, and S. Azizian, "Application of activated carbon as adsorbents for efficient removal of methylene blue: kinetics and equilibrium study," Journal of Industrial and Engineering Chemistry, vol. 20, no. 4, pp. 2317-2324, 2014.

[48] N. P. Raval, P. U. Shah, and N. K. Shah, "Malachite green "a cationic dye" and its removal from aqueous solution by adsorption," Applied Water Science, vol. 7, no. 7, pp. 3407-3445, 2017.

[49] B. H. Hameed, "Removal of cationic dye from aqueous solution using jackfruit peel as non-conventional low-cost adsorbent," Journal of Hazardous Materials, vol. 162, no. 1, pp. 344-350, 2009.

[50] D. Pathania, S. Sharma, and P. Singh, "Removal of methylene blue by adsorption onto activated carbon developed from Ficus carica bast," Arabian Journal of Chemistry, vol. 10, pp. S1445-S1451, 2017.

[51] F. Bouaziz, M. Koubaa, F. Kallel, R. E. Ghorbel, and S. E. Chaabouni, "Adsorptive removal of malachite green from aqueous solutions by almond gum: kinetic study and equilibrium isotherms," International Journal of Biological Macromolecules, vol. 105, pp. 56-65, 2017.

[52] A. Regti, M. R. Laamari, S.-E. Stiriba, and M. El Haddad, "Potential use of activated carbon derived from Persea species under alkaline conditions for removing cationic dye from wastewaters," Journal of the Association of Arab Universities for Basic and Applied Sciences, vol. 24, no. 1, pp. 10-18, 2017.

[53] A. S. Sartape, A. M. Mandhare, V. V. Jadhav, P. D. Raut, M. A. Anuse, and S. S. Kolekar, "Removal of malachite green dye from aqueous solution with adsorption technique using Limonia acidissima (wood apple) shell as low cost adsorbent," Arabian Journal of Chemistry, vol. 10, pp. S3229-S3238, 2017.

[54] K. Shen and M. A. Gondal, "Removal of hazardous Rhodamine dye from water by adsorption onto exhausted coffee ground," Journal of Saudi Chemical Society, vol. 21, pp. S120-S127, 2017.

[55] B. Royer, "Applications of Brazilian pine-fruit shell in natural and carbonized forms as adsorbents to removal of methylene blue from aqueous solutions-kinetic and equilibrium study," Journal of Hazardous Materials, vol. 164, no. 2-3, pp. 1213-1222, 2009. 
[56] M. A. M. Salleh, "Cationic and anionic dye adsorption by agricultural solid wastes: a comprehensive review," Desalination, vol. 280, no. 1-3, pp. 1-13, 2011.

[57] N. Ayawei, A. N. Ebelegi, and D. Wankasi, "Modelling and interpretation of adsorption isotherms," Journal of Chemistry, vol. 2017, Article ID 3039817, 11 pages, 2017.

[58] N. Kumara, N. Hamdan, M. I. Petra, K. U. Tennakoon, and P. Ekanayake, "Equilibrium isotherm studies of adsorption of pigments extracted from kuduk-kuduk (Melastoma malabathricum L.) pulp onto $\mathrm{TiO}_{2}$ nanoparticles," Journal of Chemistry, vol. 2014, Article ID 468975, 6 pages, 2014.

[59] E. Ajenifuja, J. A. Ajao, and E. O. B. Ajayi, "Adsorption isotherm studies of $\mathrm{Cu}$ (II) and Co (II) in high concentration aqueous solutions on photocatalytically modified diatomaceous ceramic adsorbents," Applied Water Science, vol. 7, no. 7, pp. 3793-3801, 2017.

[60] K. S. Bharathi and S. T. Ramesh, "Removal of dyes using agricultural waste as low-cost adsorbents: a review," Applied Water Science, vol. 3, no. 4, pp. 773-790, 2013.

[61] N. M. Mahmoodi, "Adsorption of textile dyes on pine cone from colored wastewater: kinetic, equilibrium and thermodynamic studies," Desalination, vol. 268, no. 1-3, pp. 117-125, 2011.

[62] N. Gupta, A. K. Kushwaha, and M. C. Chattopadhyaya, "Application of potato (Solanum tuberosum) plant wastes for the removal of methylene blue and malachite green dye from aqueous solution," Arabian Journal of Chemistry, vol. 9, pp. S707-S716, 2016.

[63] M. K. Dahri, M. R. R. Kooh, and L. B. L. Lim, "Water remediation using low cost adsorbent walnut shell for removal of malachite green: equilibrium, kinetics, thermodynamic and regeneration studies," Journal of Environmental Chemical Engineering, vol. 2, no. 3, pp. 1434-1444, 2014.

[64] S. Chowdhury, "Adsorption thermodynamics, kinetics and isosteric heat of adsorption of malachite green onto chemically modified rice husk," Desalination, vol. 265 , no. 1-3, pp. 159-168, 2011.

[65] S. Khattri and M. Singh, "Removal of malachite green from dye wastewater using neem sawdust by adsorption," Journal of Hazardous Materials, vol. 167, no. 1-3, pp. 1089-1094, 2009.

[66] P. Saha, S. Chowdhury, S. Gupta, I. Kumar, and R. Kumar, "Assessment on the removal of malachite green using tamarind fruit shell as biosorbent," Clean-Soil, Air, Water, vol. 38, no. 5-6, pp. 437-445, 2010.

[67] C. P. Sekhar, S. Kalidhasan, V. Rajesh, and N. Rajesh, "Biopolymer adsorbent for the removal of malachite green from aqueous solution," Chemosphere, vol. 77, no. 6, pp. 842-847, 2009.

[68] S. Banerjee, G. C. Sharma, R. K. Gautam, M. C. Chattopadhyaya, S. N. Upadhyay, and Y. C. Sharma, "Removal of malachite green, a hazardous dye from aqueous solutions using Avena sativa (oat) hull as a potential adsorbent," Journal of Molecular Liquids, vol. 213, pp. 162-172, 2016.

[69] J. Zhang, Y. Li, C. Zhang, and Y. Jing, "Adsorption of malachite green from aqueous solution onto carbon prepared from Arundo donax root," Journal of Hazardous Materials, vol. 150, no. 3, pp. 774-782, 2008.

[70] T. K. Murthy, "Studies on batch adsorptive removal of malachite green from synthetic wastewater using acid treated coffee husk: equilibrium, kinetics and thermodynamic studies," Microchemical Journal, vol. 146, pp. 192-201, 2019.

[71] R. Gong, Y. Jin, F. Chen, J. Chen, and Z. Liu, "Enhanced malachite green removal from aqueous solution by citric acid modified rice straw," Journal of Hazardous Materials, vol. 137, no. 2, pp. 865-870, 2006.

[72] S.-A. Ong, K. Uchiyama, D. Inadama, Y. Ishida, and K. Yamagiwa, "Treatment of azo dye acid orange 7 containing wastewater using up-flow constructed wetland with and without supplementary aeration," Bioresource Technology, vol. 101, no. 23, pp. 9049-9057, 2010.

[73] A. A. Jalil, S. Triwahyono, M. R. Yaakob et al., "Utilization of bivalve shell-treated Zea mays L. (maize) husk leaf as a lowcost biosorbent for enhanced adsorption of malachite green," Bioresource Technology, vol. 120, pp. 218-224, 2012.

[74] T. A. Khan, R. Rahman, I. Ali, E. A. Khan, and A. A. Mukhlif, "Removal of malachite green from aqueous solution using waste pea shells as low-cost adsorbent-adsorption isotherms and dynamics," Toxicological \& Environmental Chemistry, vol. 96, no. 4, pp. 569-578, 2014. 